\title{
Echocardiography in adult congenital heart disease
}

\author{
A Houston, S Hillis, S Lilley, T Richens, L Swan
}

The initial presentation of congenital heart disease in adult life is now uncommon. The specialty of adult congenital heart disease is largely concerned with long term follow up of patients with previously diagnosed lesions, many of whom have undergone a palliative or theoretically corrective procedure, and who are best managed by an appropriate specialist in a tertiary centre. Although congenital heart disease is an uncommon problem for the general cardiologist, he or she may be faced with a patient with an undiagnosed defect, may be asked to look after a patient with a complex lesion for geographical or other reasons, or may have to manage a patient who usually attends a tertiary centre but is admitted acutely with an associated illness or is pregnant. Often the exact diagnosis and previous surgical treatment is not accurately known to the echocardiographer, who is then faced with the problem of determining the basic diagnosis and previous surgical treatment before assessing the cardiac status.

In pregnancy, deterioration in the patient with a significant cardiac lesion is a recognised complication. Reassessment of minor or previously corrected abnormalities may be required, and benign murmurs are more easily heard and their significance may be questioned.

The requirements for a service for adults with congenital heart disease has been well considered in the report commissioned by the Canadian Cardiovascular Society at the 1996 consensus conference on adult congenital heart disease. The most recent amendments to this were done in August 1998 and are available on the internet. ${ }^{1}$ Recommendations are made on diagnosis, investigation, and follow up assessment. An important part is the requirement for echocardiography and in this review we will expand upon these guidelines.

Echocardiography is the mainstay in the diagnosis and follow up assessment of most patients with congenital heart disease. The literature in adults is relatively sparse, however, comprising largely case reports of unusual lesions rather than information on the common problems. Some extrapolation from experience in adolescents or younger subjects is therefore necessary. Transthoracic images in adults may be sufficiently clear for clinical use but of poor quality for illustrative purposes, and we have chosen to use a number of images from adolescents. Where it is difficult to obtain diagnostic images from a precordial site, transoesophageal echocardiography will usually give good quality images, particularly of posterior structures. Rather than repeatedly stating this for individual conditions the reader can assume this unless a statement is made to the contrary. In addition it may often be necessary to move the patient to lie on the left or right side as necessary to obtain the optimal images. The best position for specific complex lesions cannot be predicted with certainty and the echocardiographer should try a number of these as appropriate. In many paediatric centres four chamber views are shown with the apex of the scanning plane at the bottom to provide a more easily appreciated image. However, most adult centres show them with the apex upward so we have followed this practice.

Consideration is given to the echocardiographic findings in the primary diagnosis of defects commonly presenting in adult life, and those being followed to identify the development of complications of known defects, whether they be relatively simple unoperated lesions or the more complex ones following surgery. A number of publications provide detailed information on cardiac morphology, terminology, and echocardiography but these are most relevant to initial diagnosis of complex lesions and cannot be considered in detail in this review. ${ }^{2-4}$

In adult cardiology practice the initial diagnosis of a congenital cardiac defect is an uncommon, though regular, occurrence. Most of these lesions are relatively "simple" in terms of cardiac anatomy and are easily recognised, but occasionally more complex ones present a diagnostic problem. There is no definitive information on the presentation of congenital heart disease in adults, but representation of the defects likely to present late can be obtained from two studies in the German literature. One study involved 183 newly diagnosed defects in 161 patients of whom $20 \%$ were referred for surgery, ${ }^{5}$ and the other involved 178 adults undergoing primary surgical correction ${ }^{6}$ (table 1). The literature contains many reports of the primary diagnosis of less common defects such as cor triatriatum, corrected transposition, coronary artery fistula, and sinus of Valsalva aneurysm, these largely having been accepted for publication because of their rarity value.

\section{Atrial septal defect}

Atrial septal defects are detected regularly at an adult echocardiography service as an incidental finding; study of the atrial septum is also undertaken to exclude a defect in young patients with a stroke ${ }^{7}$ or before undertaking activities such as diving. ${ }^{8}$ The defect can be in the central part of the atrial septum (the ostium secundum defect found in $66 \%$ of late presenting defects), high in the septum in relation to the entrance of the superior vena cava (sinus venosus defect found in $10 \%$ ), or low between 
Table 1 Percentage of specific diagnoses reported on initial recognition ${ }^{6}$ and primary correction ${ }^{6}$ of congenital heart disease in adult life

\begin{tabular}{lcc}
\hline & $\begin{array}{l}\text { Initial diagnosis } \\
\text { in 61 adult } \\
\text { patients }\end{array}$ & $\begin{array}{l}\text { Primary corrective } \\
\text { surgery in 178 adult } \\
\text { patients }\end{array}$ \\
\hline ASD or aneurysm & 39 & 57 \\
VSD or aneurysm & 15 & 3 \\
Pulmonary stenosis & 8 & 3 \\
Valve or subaortic & 5 & 5 \\
$\quad$ stenosis & 4 & 3 \\
APVD & 4 & 5 \\
AVSD & 4 & 3 \\
Arterial duct & 3 & 7 \\
Coarctation & 1 & 3 \\
Ebstein's anomaly & $<1$ & 3 \\
Tetralogy of Fallot & $<1$ & 1 \\
Univentricular heart & $<1$ & $<1$ \\
Cor triatriatum & $<1$ & $<1$ \\
Corrected TGA & $<1$ &
\end{tabular}

ASD, atrial septal defect; VSD, ventricular septal defect; APVD, anomalous pulmonary venous drainage; AVSD, atrioventricular septal defect; TGA, transposition of the great arteries.

Table 2 Atrial septal defect (ASD)

Suspect if M mode evidence of right ventricular volume overload

- increased size and abnormal septal motion

Image atrial septum with 4 chamber views for secundum or primum defect

Tilt anteriorly for sinus venosus defect if no other apparent

Contrast imaging studies if uncertain if ASD present

Transoesophageal echocardiography for definitive imaging of

ASD

Measure the size of the defect and assess rim of atrial tissue

Measure right ventricular pressure from tricuspid regurgitation signal

Remember other causes of right ventricular volume overload

- check for significant tricuspid or pulmonary

regurgitation

- look for an anomalous vein

the coronary sinus orifice and the inferior vena cava (coronary sinus defect found in less than $5 \%$ ). The ostium primum atrial septal defect, classified as a partial atrioventricular septal defect, lies low in the septum, and reaches up to the crux of the heart and the atrioventricular valves ( $15 \%$ of adult atrial septal defects), and is associated with anomalies of the inlet valves. A report on the echocardiographic findings in

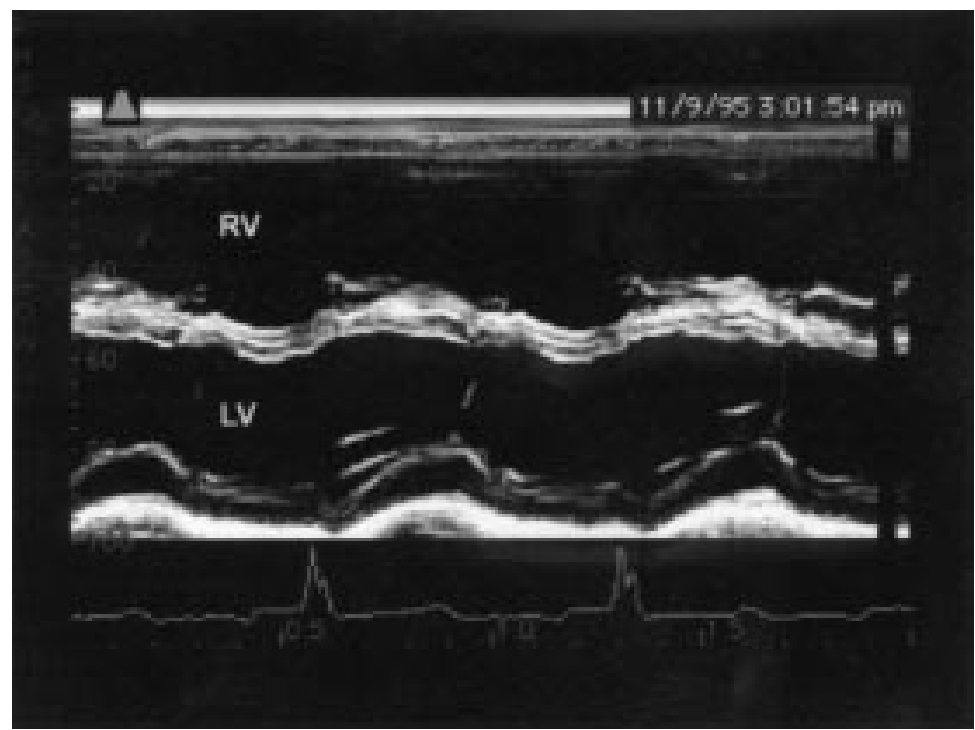

Figure $1 M$ mode study from a patient with a large secundum atrial septal defect. There is marked increase in the right ventricle diastolic dimension, and paradoxical septal motion with the septum moving in parallel with the posterior left ventricular wall. RV, right ventricle; LV, left ventricle.
24458 patients aged 16-84 found atrial septal anomalies in 294 subjects: secundum defects in $46 \%$, primum defects in $11 \%$, atrial septal aneurysms in $24 \%$, and superior sinus venosus defects with anomalous pulmonary venous return in $6 \%$. A patent foramen ovale was found in $13 \%$ of this group and in the total group of 24458 it could be demonstrated in $0.16 \%$ with transthoracic imaging and in $5.7 \%$ with transoesophageal imaging. ${ }^{9}$

An atrial septal defect should be suspected on echocardiography if there is evidence of right ventricular volume overload (table 2), ${ }^{10}$ characterised on a standard long axis $M$ mode study by right ventricle enlargement and paradoxical septal motion (fig 1). The latter describes the appearance in systole that the ventricular septum moves anteriorly or shows little movement. The size of the left to right shunt through the atrial septal defect is reflected in the right ventricular dimension, ${ }^{11}$ but the appearance is also found with other causes of volume overload, such as anomalous pulmonary venous drainage or tricuspid or pulmonary regurgitation. An apical, parasternal or subcostal four chamber view is used to show the atrial septum (fig 2). The subcostal view should be sought since the intra-atrial septum is perpendicular to the ultrasound beam giving optimal images. ${ }^{12}$ Even with good equipment and careful study it can be difficult to diagnose a secundum lesion on cross

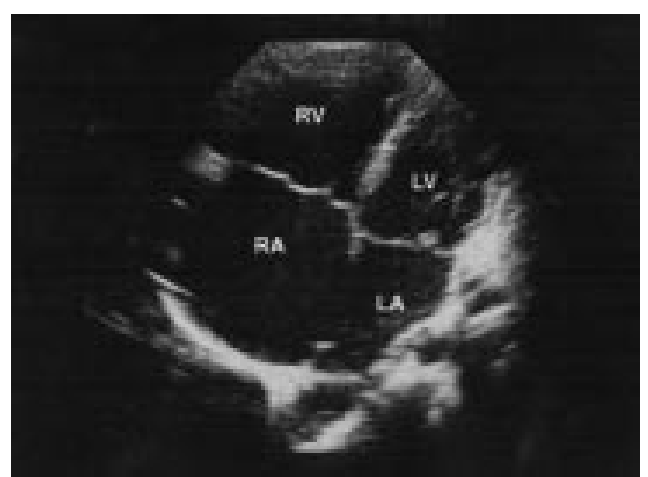

Figure 2 Parasternal four chamber view in a patient with a large secundum atrial septal defect. There is enlargement of the right ventricle and a large gap in the central part of the atrial septum. $R A$, right atrium; $L A$, left atrium; others as before.

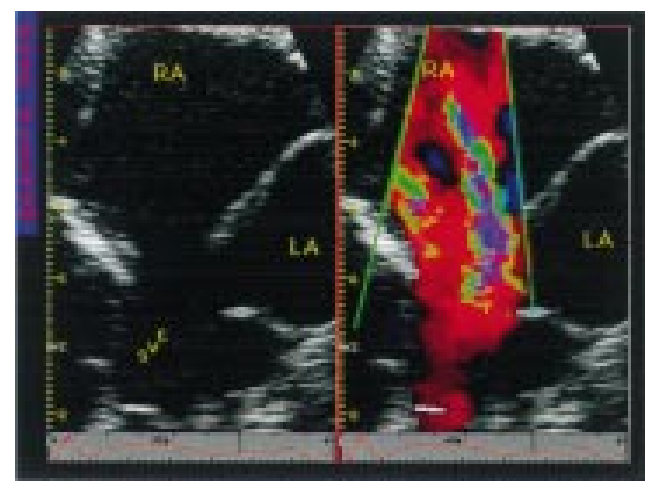

Figure 3 Cross sectional and colour images of a high sinus venosus atrial septal defect. The scanning plane has been tilted upwards to show the entry of the superior vena cava, which is shown to override the atrial septum. An anomalous pulmonary vein is not shown. SVC, superior vena cava; others as before. 

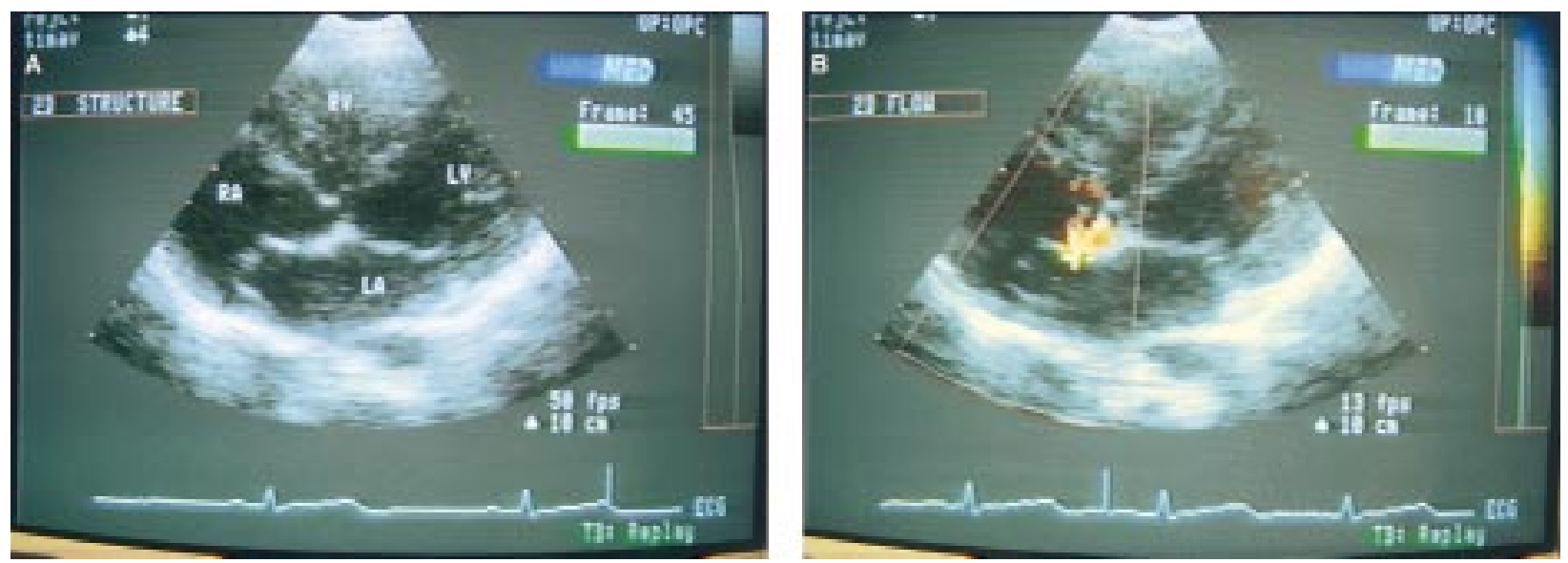

Figure 4 Cross sectional and colour images from a woman with an atrial septal aneurysm. (A) The aneurysm bulges into the right atrium and there are areas of echo dropout which might suggest a defect. (B) Colour is necessary to determine whether there is a defect and identify its site.

sectional echocardiography. A superior sinus venosus defect can theoretically be shown by more anterior angulation of the scanning plane to show the high septum at its junction with the superior vena cava, which appears to override the defect (fig 3), but transoesophageal echocardiography is usually needed. A number of adults have an aneurysm of the atrial septum, apparent as a central bulge into the right atrium (fig 4). In itself this is of no clinical significance unless there is a defect. Where an atrial septal defect is considered to be present this should be confirmed using colour Doppler which, in addition, may also show a defect not

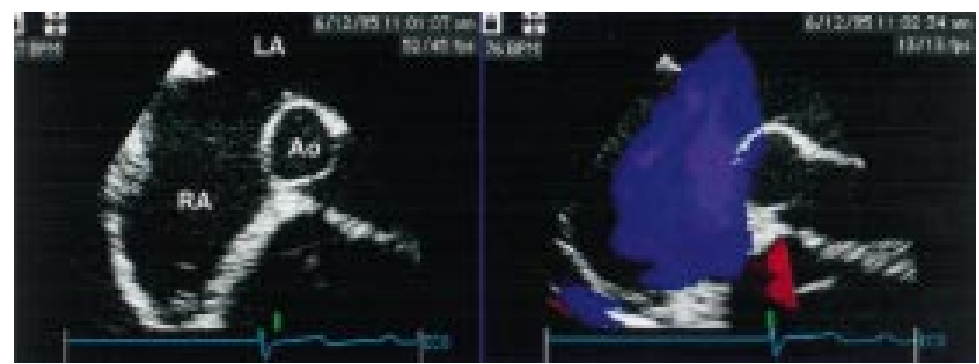

Figure 5 Transoesophageal echocardiography images in a patient with a large secundum atrial septal defect showing the defect and flow from the left to right atrium. The defect. reaches to near the aorta and only a small edge of atrial septum is seen next to it at this margin. Ao, aortic root; others as before.
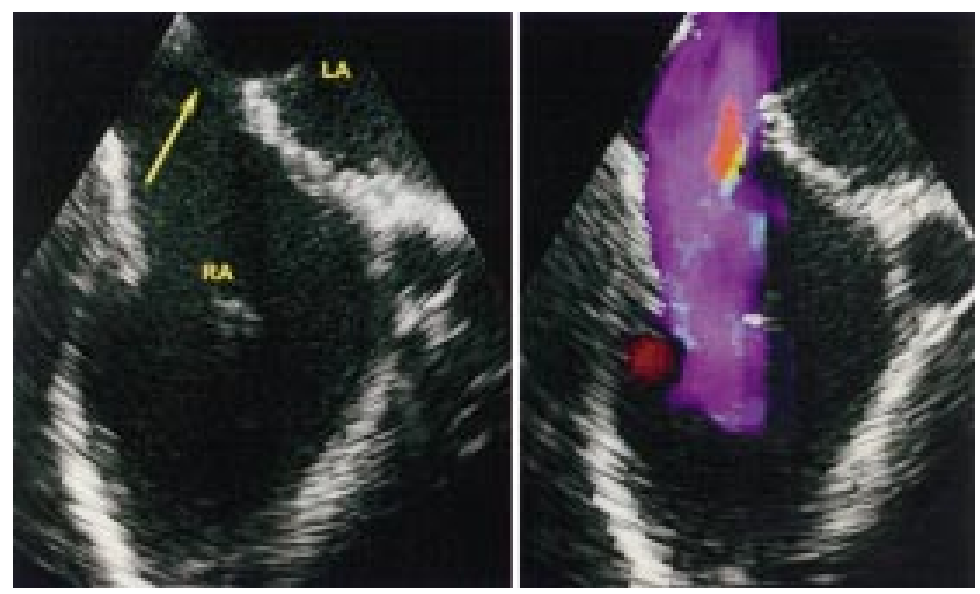

Figure 6 Transoesophageal echocardiography images in a patient with a sinus venosus atrial septal defect showing the defect (arrow) and flow from the left (LA) to right (RA) atrium. The defect is shown in the upper and posterior part of the septum at the entrance of the superior vena cava. apparent on imaging. Care should be taken not to mistake the signal of flow into the right atrium from the superior vena cava or tricuspid regurgitation for atrial septal defect flow. Spectral Doppler is of little practical value. It shows transatrial flow to be mainly left to right with a very brief signal of right to left flow in early systole.

Atrial lesions are difficult to image with transthoracic echocardiography; septal dropout is common and its finding does not confirm the presence of a defect, particularly if present in only one view. Transoesophageal imaging is a more sensitive way to detect and characterise an atrial septal defect, ${ }^{13}{ }^{14}$ which is readily demonstrated in a transverse plane. The secundum defect lies centrally (fig 5) and the sinus venosus more superiorly (fig 6 ), with the mouth of the superior vena cava overriding its superior margin. ${ }^{14}$ Transoesophageal imaging is essential during transcatheter closure of a secundum atrial septal defect, to define the margins of the defect ${ }^{15}$ and assist with deployment of the device.

The foramen ovale has been shown to be "probe patent" in up to $25 \%$ of the population at postmortem examination ${ }^{16}$ and in about $6 \%$ with transoesophageal imaging. ${ }^{9}$ A patent foramen ovale or a small atrial septal defect may be significant as a potential source of right to left shunt and of relevance to divers or in the aetiology of a paradoxical embolism. Their distinction is of little practical clinical importance. Exclusion or confirmation of the presence of a small atrial communication is improved for both thoracic and oesophageal imaging by the use of an echocardiographic contrast medium. ${ }^{17}$ A "negative contrast effect" with non-contrast containing blood crossing into the right atrium provides direct evidence of a shunt. Transoesophageal echocardiography with contrast has been shown to be the most sensitive technique for detection of a patent foramen ovale and, if taken as the "gold standard", the sensitivity of detection is $7 \%$ for transthoracic echocardiography, rising to $50 \%$ if contrast is used, and $79 \%$ for transoesophageal echocardiography. Transoesophageal imaging is also useful in the detection and assessment of atrial septal aneurysms, which have 


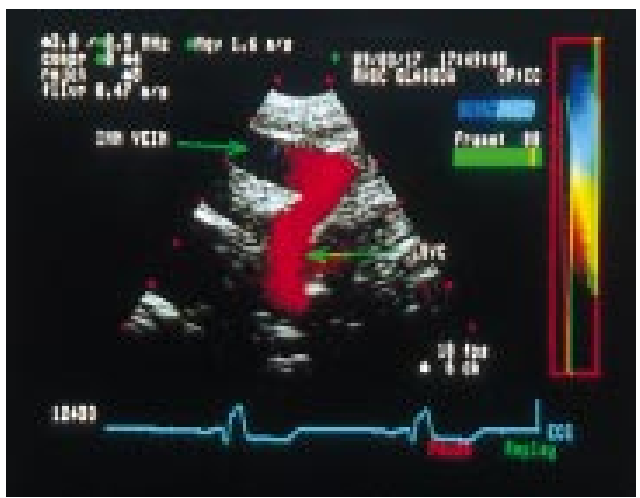

Figure 7 Left parasaggital view in a patient with partial anomalous pulmonary venous drainage of the left upper pulmonary vein to the innominate. The pulmonary vein enters a left ascending vein (LSVC) which joins the innominate vein (Inn vein). Colour shows the flow is upwards to the innominate.

been reported in $2-10 \%$ of patients undergoing transoesophageal echocardiography, with many associated with atrial shunting. ${ }^{18}$

The pulmonary artery pressure should be estimated from the signal of tricuspid regurgitation. Common associations with an atrial septal defect should be sought, in particular mitral valve prolapse or an anomalous pulmonary vein, reported as $10 \%$ with secundum and $80 \%$ with sinus venosus defects. ${ }^{19}$ Anomalous pulmonary venous drainage occurs when one or more of the pulmonary veins enter the systemic venous system or right atrium. The haemodynamic effect is similar to that of an atrial septal defect and echocardiography will show right ventricular volume overload. If no cause for this is readily apparent it is prudent to search for an anomalous vein which may enter the innominate (fig 7 ), superior vena cava, right atrium, or inferior vena cava. They can be difficult to image and colour Doppler may simplify their recognition. A right upper pulmonary vein draining into the superior vena cava associated with a sinus venosus defect can be difficult to show, even with transoesophageal echocardiography.

\section{Atrioventricular septal defect}

An atrioventricular septal defect occurs when the atrial and ventricular septae do not fuse, leaving a confluent defect with a common

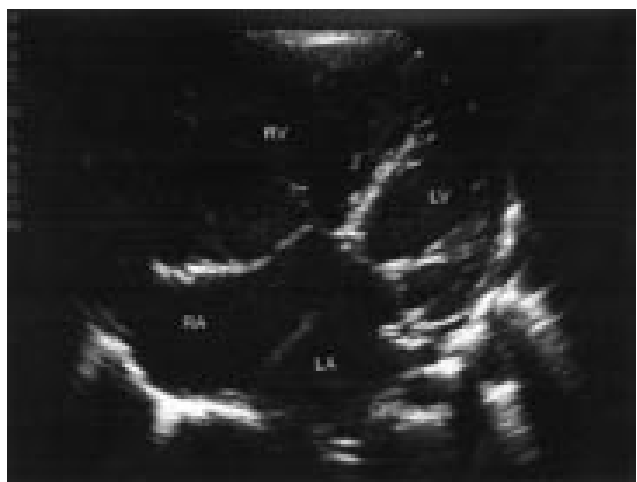

Figure 8 Parasternal four chamber view in a patient with an ostium primum atrial septal defect. The atrioventricular valves are attached to the edge of the ventricular septum at the same level and there is a large gap in the septum primum between the ventricular and the atrial septae. atrioventricular valve ring. In the partial defect (or a primum atrial septal defect) there are two separate atrioventricular valve orifices, with the anterior leaflet divided into left and right components inserted directly into the rim of the ventricular septum; in a complete defect the anterior leaflet is free floating, allowing shunting between both the atria and ventricles. In association the left (mitral) component of the valve has an apparent anterior cleft at the point of apposition of the abnormal central and lateral leaflets, and regurgitation is common.

In the primum defect there will be evidence of right ventricular volume overload on $M$ mode echocardiography. A four chamber view will show the gap between the septae, with the anterior valve leaflets attached to the rim of the ventricular septum at the same level rather than the usual offsetting ${ }^{20}$ (fig 8); colour Doppler shows flow through the atrial defect. Detailed anatomy of the atrioventricular valve can be ascertained from a subcostal short axis view, ${ }^{22}$ but this is difficult in adults and the main importance is to assess the degree of regurgitation. After surgical correction of these defects residual shunts should not be large, but valve regurgitation is common and the aim of long term follow up is largely to keep this under review. In addition subaortic stenosis can develop after repair and should be sought.

\section{Persistent arterial duct}

A duct can be shown in a suprasternal arch view, short axis view of the great arteries, or a parasaggittal view ${ }^{23}$ from the upper left sternal edge as a continuation of the pulmonary artery into the descending aorta (fig 9) (table 3). Colour Doppler simplifies diagnosis and should show a continuous flame shaped jet arising at the mouth of the duct (distal main pulmonary artery near junction with the left pulmonary artery) and directed along the superolateral wall of the main pulmonary artery. ${ }^{24}$ The spec-

\section{Table 3 Patent ductus arteriosus}

Identify with imaging and colour Doppler studies

- short axis great artery and aortic arch views of distal main pulmonary artery

Spectral recording of ductal flow signal to assess pulmonary pressure

Check right ventricular pressure from signal of tricuspid regurgitation

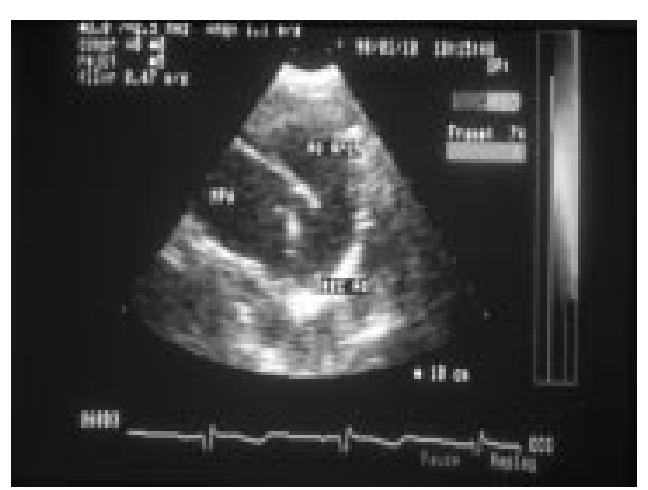

Figure 9 Left parasaggital view of the arterial duct in teenage girl. The duct is shown as a continuation of the main pulmonary artery (MPA) into the descending aorta (Desc Ao). Ao Arch, aortic arch; others as before. 


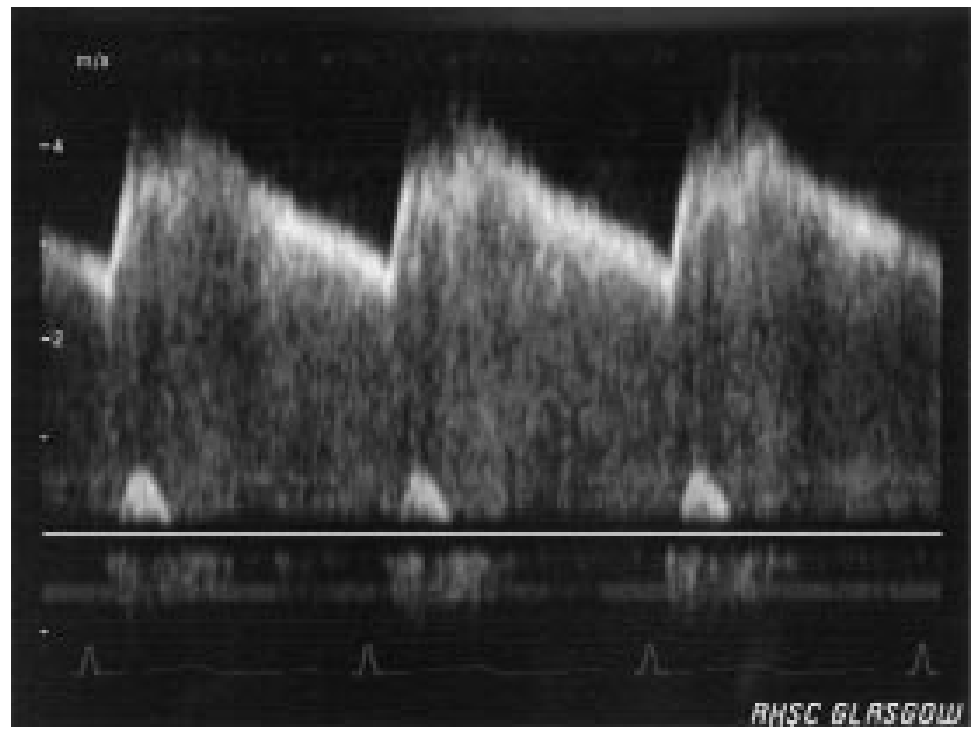

Figure 10 Spectral Doppler signal of ductal flow in ductus arteriosus with low pulmonary artery pressure. The signal is a continuous one reaching its maximum velocity $(4.3 \mathrm{~m} / \mathrm{s})$ in mid-systole and then falls off until just after the $R$ wave.

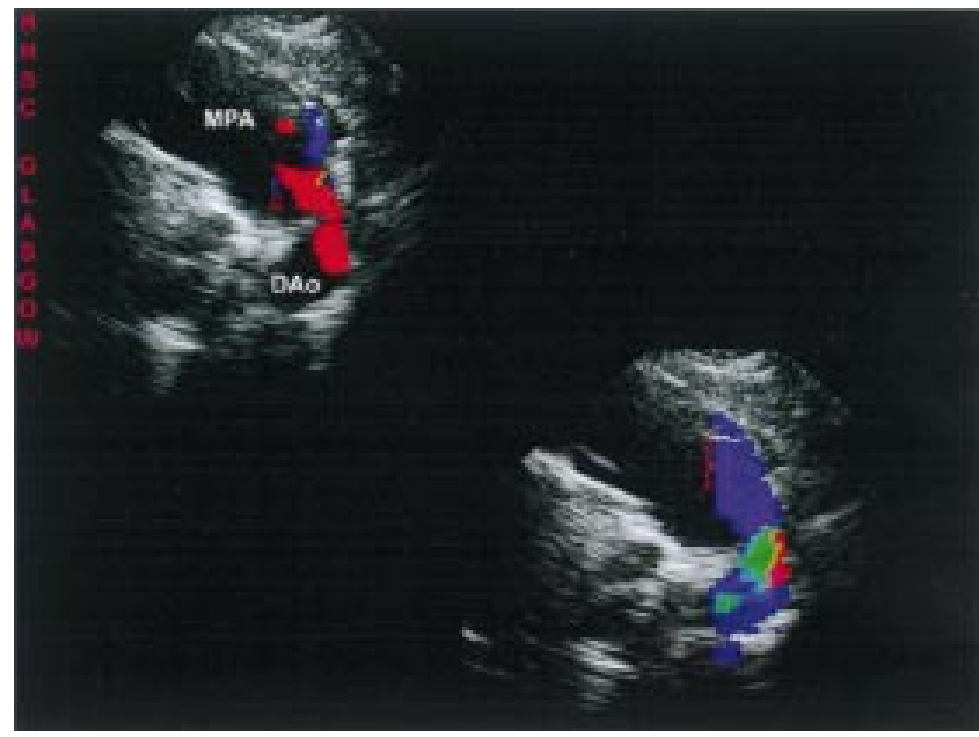

Figure 11 Left parasternal views in a woman with Eisenmenger's syndrome and patent ductus arteriosus. The duct is imaged as a continuation of the main pulmonary artery (MPA) into the descending aorta (DAo). Flow is bidirectional, from the pulmonary artery to aorta in systole (top) and aorta to pulmonary artery in diastole (bottom).

tral signal in a patient with low pulmonary artery pressure shows continuous flow, with highest velocity in mid-systole and lowest at end diastole (fig 10), the audio signal sounding very much like that heard with the stethoscope. With pulmonary artery pressure at systemic level the ductal flow is bidirectional, from the aorta to pulmonary artery in diastole and pulmonary artery to aorta in systole (fig 11). Transoesophageal echocardiography may show the ductal flow signal in patients where satisfactory transthoracic images cannot be obtained. ${ }^{25}{ }^{26}$ It is important to be aware that tiny ducts not audible with the stethoscope (the "silent duct") (fig 12) can be shown with colour Doppler and are best considered as a normal variant, ${ }^{27}$ similar to physiological mitral regurgitation.

A similar clinical finding of a continuous murmur (but in a relatively low position) is

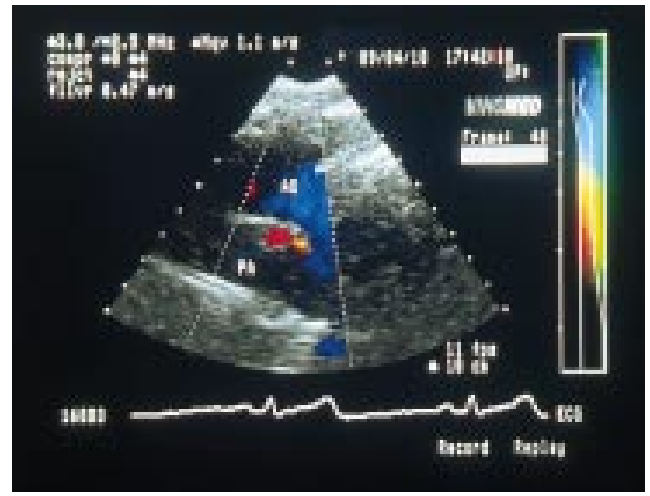

Figure 12 Colour Doppler demonstration of flow through the duct into the pulmonary artery in a woman with a "silent" duct. PA, pulmonary artery; $A O$, aorta; others as before.

heard with a coronary artery or sinus of Valsalva fistula. A coronary artery fistula can present at any age. ${ }^{28}$ On echocardiography the coronary artery will be dilated ${ }^{29}$ (fig 13), and with a fistula from the left coronary system this is immediately recognisable on a parasternal long axis view as a circular echo free space just posterior to the aortic root. Colour Doppler will show flow into the communicating chamber (fig 13). ${ }^{30} \mathrm{~A}$ sinus of Valsalva fistula is recognised from the colour flow signal from the aortic root into the appropriate chamber (usually right ventricle or right atrium) (fig 14). ${ }^{31}$

\section{Ventricular septal defect}

Small ventricular septal defects are difficult to show with imaging alone; identification will require colour Doppler demonstration of flow through the ventricular septum into the right ventricle (fig 15), the Doppler signal generally being towards the transducer but on occasions away from it (table 4). The best echocardiographic view will be dependent on the ventricular septal defect site. The study should include standard precordial views but a more medial position may be helpful for some apical defects. The echocardiographic identification of the site of a ventricular septal defect has been well described..$^{32}$ The spectral Doppler signal shows a rapid early systolic rise to a midsystolic peak and rapid late systolic fall (fig 16), its shape rather similar to that of atrioventricular valve regurgitation. The maximum velocity of flow through the defect provides a relatively accurate measurement of the pressure difference between the ventricles. ${ }^{34}{ }^{35}$ The right ventricular pressure can theoretically be estimated by subtracting the interventricular pressure gradient from systolic blood pressure - that is, the left ventricular pressure. However, there are potential inaccuracies in this calculation so it is more prudent to take the velocity into account; a high velocity indicates low right ventricular and pulmonary pressure and a low velocity a high pressure. With Eisenmenger's syndrome the signal is of low velocity and shows bidirectional flow (fig 17). Transoesophageal imaging will provide a clear image of the defect when standard views are unsatisfactory (fig 18). Although early reports suggested that the shunt could be quantitated by measuring the vessel 

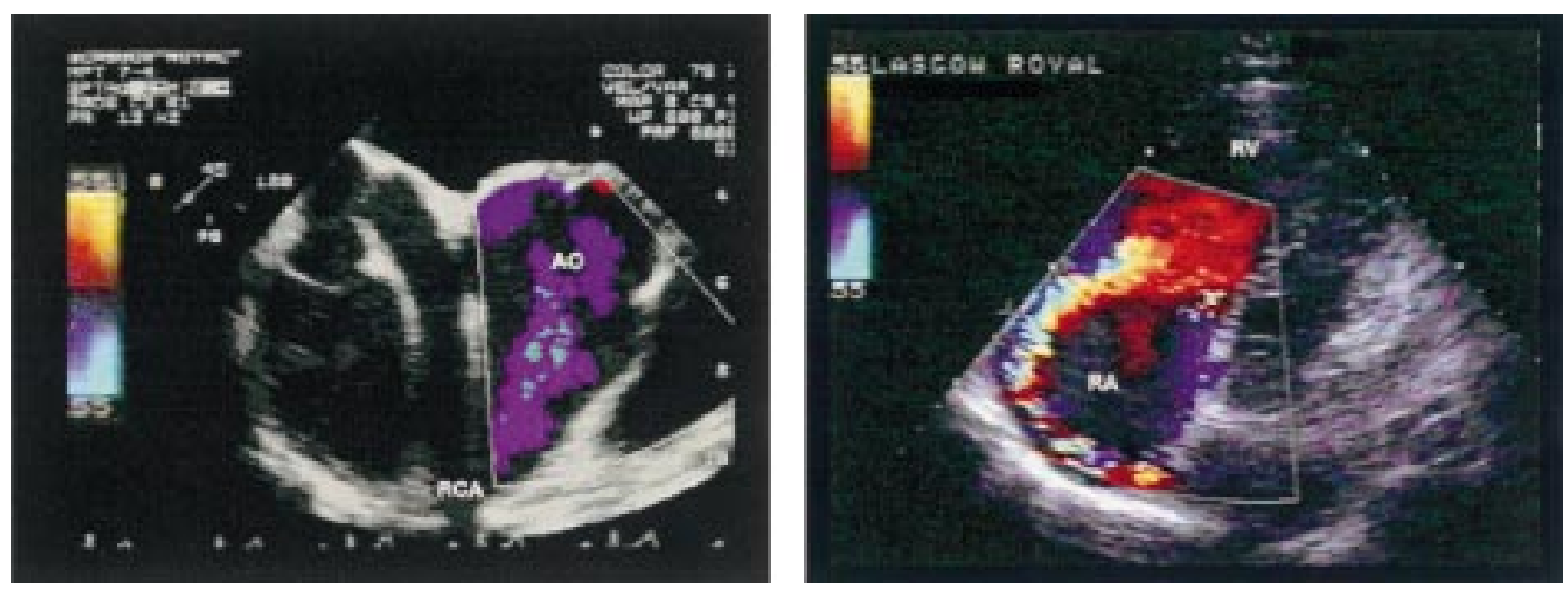

Figure 13 Images from a man with a fistula from the right coronary artery to the right atrium. The transoesophageal image (left) shows a very dilated right coronary artery which passes anteriorly and then sharply posteriorly. The transthoracic image (right) shows the jet flowing into the right atrium towards the right wall and then anteriorly; others as before.

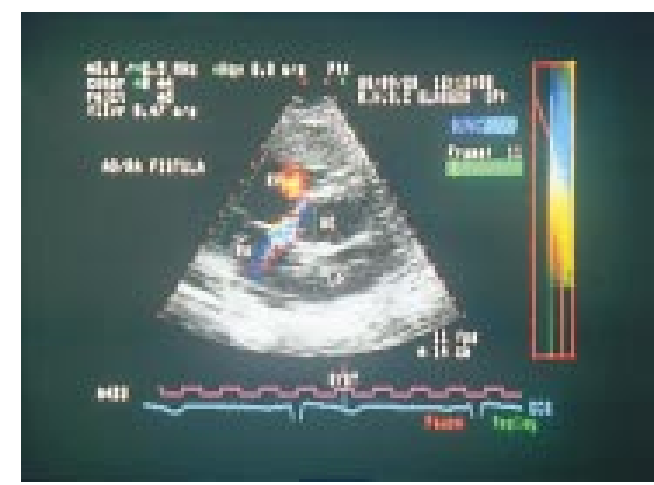

Figure 14 Colour Doppler image in a man with a sinus of Valsalva aneurysm showing flow from the aortic root into the right atrium.

Table 4 Ventricular septal defect

Identify with imaging and colour Doppler studies of ventricular septum

- long axis, short axis and 4 chamber sweeps

Record spectral velocity through the septum and calculate

right ventricular pressure

If subaortic defect check for right coronary cusp prolapse and aortic regurgitation

Check right ventricular pressure from signal of tricuspid regurgitation

Measure left atrial and ventricular sizes for increase caused by large shunt

area with imaging and mean flow velocity with Doppler, this has not been substantiated and is of little practical value. Increase in left sided chamber dimensions would be consistent with high pulmonary blood flow.

When there is outlet extension of a membranous defect into a subaortic position the Venturi effect can suck the right coronary cusp down causing prolapse (fig 19) and aortic regurgitation. ${ }^{36}$

\section{Pulmonary valve disease}

Images of the right ventricular outflow tract, pulmonary valve, and artery are best obtained using either a parasternal short axis great artery view, or a low parasternal four chamber view with upward angulation (table 5). The exact site of obstruction can be difficult to ascertain ${ }^{37}$ but colour Doppler may be helpful. Transoesophageal echocardiography may provide

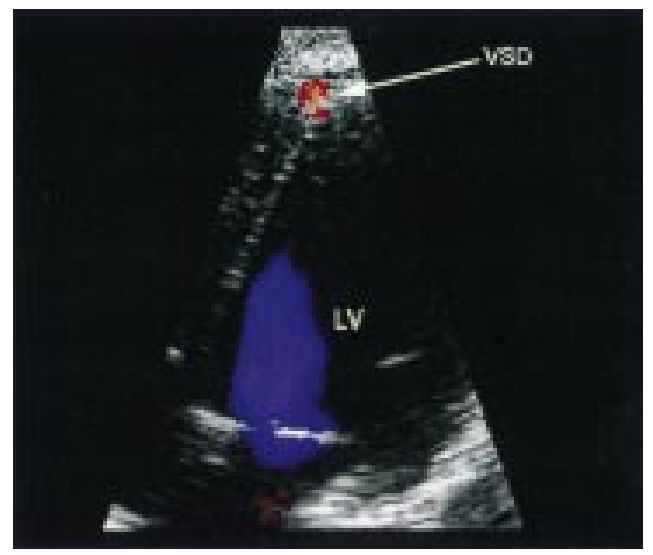

Figure 15 Colour Doppler image of a tiny apical ventricular septal defect (VSD). The defect cannot be shown with imaging alone but is readily identified with colour.

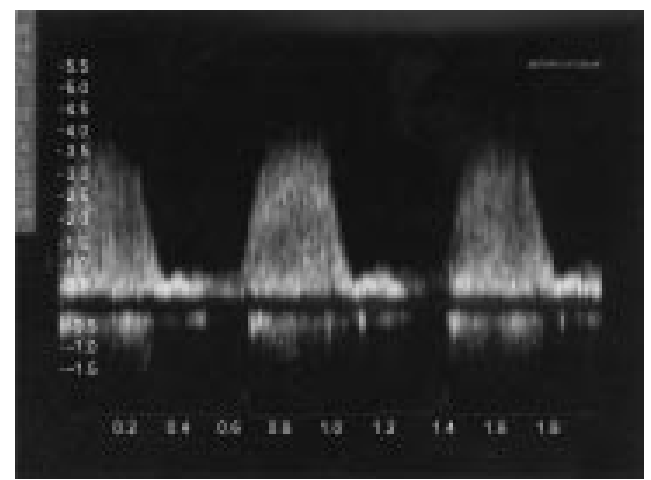

Figure 16 Spectral Doppler recording of flow through a small ventricular septal defect from left to right ventricle. It demonstrates a sharp rise in systole to the mid-systolic plateau and then a sharp fall at end systole. The maximum velocity of about $4 \mathrm{~m} / \mathrm{s}$ represents a pressure difference between the ventricles of about $64 \mathrm{~mm} \mathrm{Hg}$.

additional information, ${ }^{38}$ but in general echocardiography is poor at visualising the pulmonary artery anatomy, particularly distal lesions, and non-invasive assessment is better undertaken with magnetic resonance imaging (MRI). Since the pulmonary artery pressure is low in pulmonary stenosis, there is little difference between the instantaneous and peak to peak gradients; the spectral Doppler assess- 


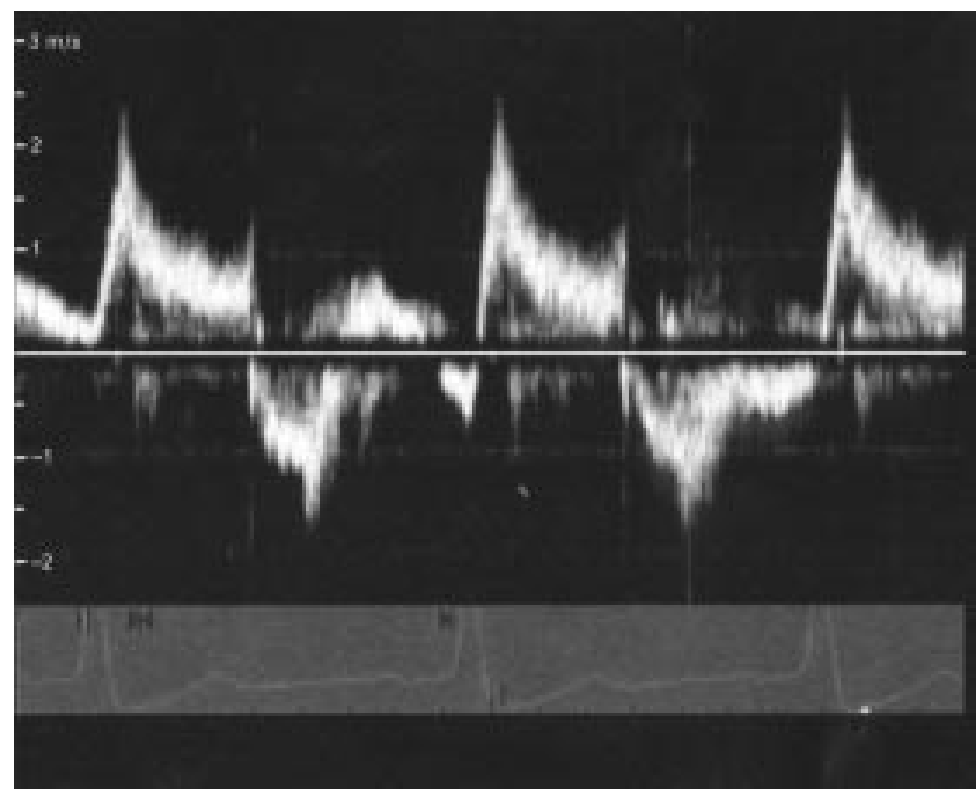

Figure 17 Spectral Doppler recording of flow through a ventricular septal defect in a woman with Eisenmenger's syndrome. The velocity is low (maximum $2.3 \mathrm{~m} / \mathrm{s}$ ) and the pattern demonstrates flow from left to right (above the line) in systole and bidirectional in diastole.

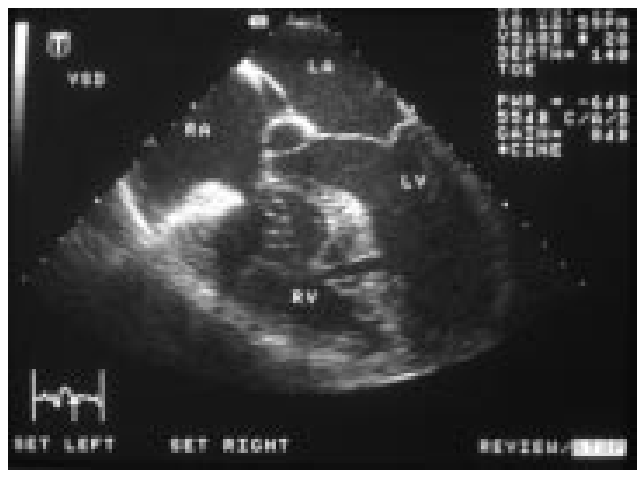

Figure 18 Transoesophageal study showing a mid-muscular ventricular septal defect in a man in whom it was poorly seen with transthoracic echocardiography.

ment of gradient bears a close relation to a simultaneously measured one ${ }^{39}$ though it varies considerably with the patient's physiological state. ${ }^{40}$

Pulmonary regurgitation on Doppler is a physiological finding in $90 \%$ of normal

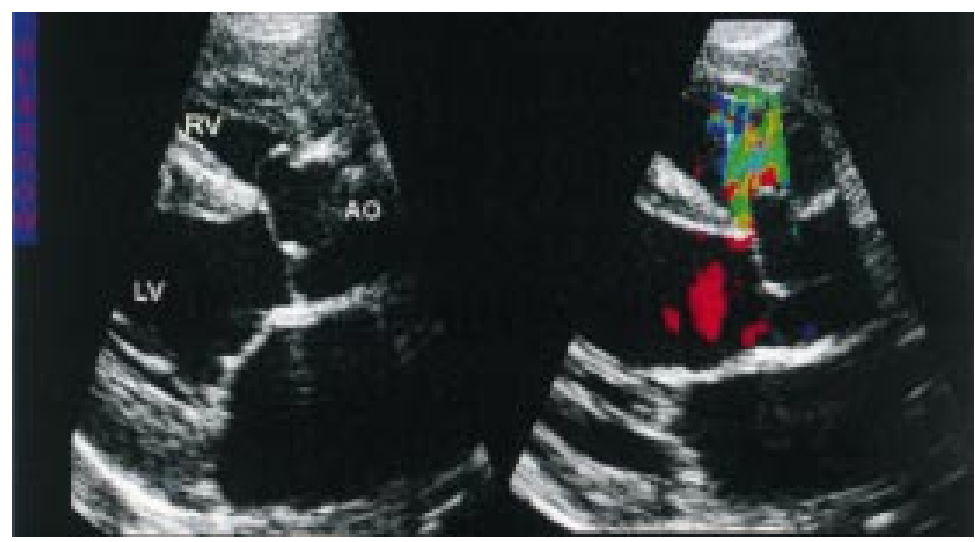

Figure 19 Long axis views in a patient with subaortic ventricular septal defect and aortic valve prolapse. The image shows that the right coronary cusp is prolapsing into the defect and limiting its size and the colour demonstrates the residual flow through the lower part of the ventricular septal defect.

\section{Table 5 Pulmonary stenosis}

Identify area of narrowing with imaging and colour Doppler studies

- parasternal outflow tract and short axis great artery views Measure maximum spectral velocity at any areas of aliasing Assess severity of pulmonary regurgitation

- right ventricular size and backflow from pulmonary artery into the ventricle

Check right ventricular pressure from signal of tricuspid regurgitation

Transoesophageal imaging may be of assistance

Remember in distal obstruction imaging poor and spectral velocity unreliable

subjects, ${ }^{41}$ the signal being a narrow one passing only a very short distance into the right ventricle. Echocardiographic criteria to assess the severity of pulmonary regurgitation are largely subjective. It is generally accepted that increasing severity of regurgitation is suggested by increasing right ventricular volume overload (large right ventricle and paradoxical septal motion) and more distal retrograde flow in the pulmonary arterial tree, and the further the jet reaches back into the right ventricle.

\section{Tetralogy of Fallot}

Patients with tetralogy of Fallot attending an adult echocardiography service have usually had radical reparative surgery. The common residual lesions are pulmonary regurgitation or obstruction at right ventricular outflow tract or branch level, and occasionally a residual ventricular septal defect or tricuspid regurgitation.

Obstructive lesions are sought using the techniques described for pulmonary stenosis with transthoracic or transoesophageal (fig 20) imaging. A high velocity spectral signal will indicate an obstructive lesion, but since there can be narrowing at more than one level and a distal lesion may not be visualised, it is not possible to ensure that there is not an additional lesion. Doppler does not give an accurate estimate of gradient at branch level. A high right ventricular pressure assessed from the signal of tricuspid regurgitation indicates significant obstruction or pulmonary hypertension. If there is severe tricuspid regurgitation the right ventricle may not generate a high pressure and a significant obstruction can occur without a high right ventricular pressure or gradient (table 6 ).

Moderate to severe pulmonary regurgitation occurs in up to $30 \%$ of patients after valvotomy or a transannular patch. ${ }^{42}$ In this situation there is a large right ventricle and outflow tract (fig

\section{Table 6 Postoperative complete repair of tetralogy of Fallot}

Measure right ventricular size and assess function

Assess septal motion and right ventricular hypertrophy

Image and colour of right ventricular outflow tract, pulmonary artery and branches

Measure maximum velocity at any areas of aliasing

Assess pulmonary and tricuspid regurgitation from colour signals

Measure right ventricular pressure from tricuspid regurgitation velocity

Look for a residual ventricular septal defect

Measure aortic root size and look for aortic regurgitation

Remember in distal obstruction imaging poor and spectral velocity unreliable

- right ventricular pressure may give better indication of obstruction 


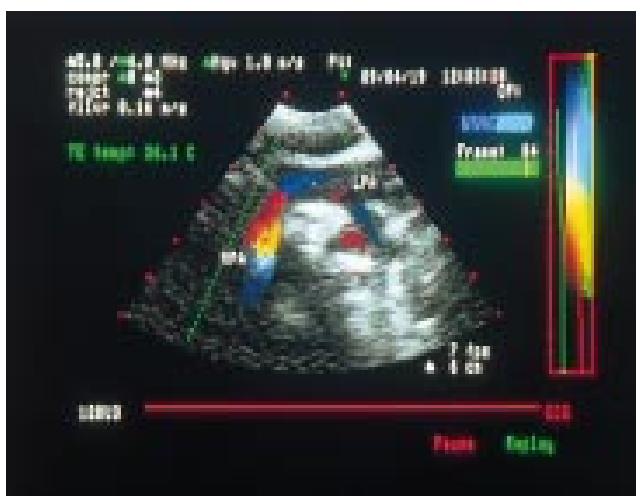

Figure 20 Transoesophageal image of the main pulmonary artery (MPA) and left pulmonary artery (LPA) in a patient who has undergone repair of tetralogy of Fallot. The narrowing in the MPA is indicated by the increased flow velocity on colour Doppler. The LPA and its branches are of good size with no narrowed areas.

21), and severity of regurgitation may be assessed from the right ventricular volume overload and the Doppler backflow signal in the pulmonary artery and into the right ventricle, as previously described. There may be a residual ventricular septal defect but the shunt size is difficult to assess. The aortic root dimension is increased in childhood as part of the condition and this may be still be apparent in adult life. ${ }^{42}$

\section{Pulmonary artery conduit}

Obstruction in a pulmonary artery conduit develops from calcification of a biological valve or the ingrowth of tissue. Good images are seldom obtained, even in slim children, and MRI is a better way to demonstrate narrowing. ${ }^{43}$ The shape of the prosthesis means that a spectral Doppler signal is likely to underestimate the transconduit gradient. Similar problems arise with transoesophageal echocardiography. Most of these patients will have tricuspid regurgitation and serial measurements of right ventricular pressure is the best echocardiographic means of assessing the progression of any obstruction (table 7).

\section{Aortic disease}

Most adult cardiologists and technicians have considerable experience with aortic valve disease and this will not be considered. Left ventricular outflow tract obstruction can occur at subvalve or supravalvar level (table 8 ).

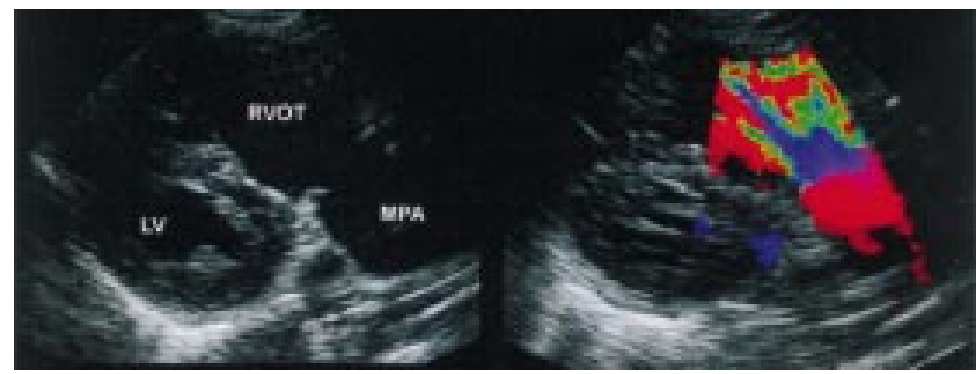

Figure 21 Views along the right ventricular outflow tract (RVOT) and main pulmonary artery in a patient who has undergone repair of tetralogy of Fallot. The right ventricle, outflow tract and pulmonary artery are dilated and there is jet of pulmonary regurgitation occupying the full width of the pulmonary ring.
Table 7 Right ventricle to pulmonary artery conduit

Measure right ventricular size and assess function

Attempt to image conduit and measure maximum velocity at any areas of aliasing

Measure right ventricular pressure from tricuspid regurgitation velocity

Transoesophageal echocardiography study may help but may also be inconclusive

Remember that imaging and Doppler are most unreliable

- right ventricular pressure gives better indication of obstruction

- MRI may be more appropriate

Table 8 Aortic stenosis

Assess the aortic valve morphology and sub- and supravalve areas

Measure the aortic root (at 3 levels if dilated)

Measure left ventricle dimensions and assess function

Measure septal and posterior wall thickness to quantify hypertrophy

Identify area of narrowing with imaging and colour Doppler studies

Measure maximum spectral velocity from at least 2 site - apical 5 chamber, suprasternal, right parasternal

Assess severity of aortic regurgitation

- left ventricular size and width of backflow jet into the ventricle

Transoesophageal imaging may be of assistance to determine site of obstruction

Remember spectral assessment of gradient unreliable in subaortic stenosis

In a parasternal long axis view a subaortic fibromuscular or membranous obstruction may be shown (fig 22). The complete margin is often not apparent and if there is doubt colour Doppler will indicate that the obstruction is below valve level. An apical long axis or five chamber view ${ }^{44}$ better shows the subaortic obstruction; when there is doubt, transoesophageal imaging will provide very clear images of the left ventricular outflow tract ${ }^{45} 46$ (fig 23). With M mode echocardiography subaortic stenosis is suggested by early closure and coarse systolic fluttering of the aortic valve. ${ }^{47}$ Spectral Doppler assessment of peak instantaneous pressure gradient in subaortic stenosis must be interpreted with caution since underestimation and overestimation can occur. Subaortic stenosis is almost invariably associated with mild aortic regurgitation and if a subaortic membrane is present the aortic valve must be carefully examined for distortion and regurgitation. Supravalvar aortic stenosis can be demonstrated in long axis views of the ascending aorta with imaging and colour Doppler. It can take the form of a relatively discrete

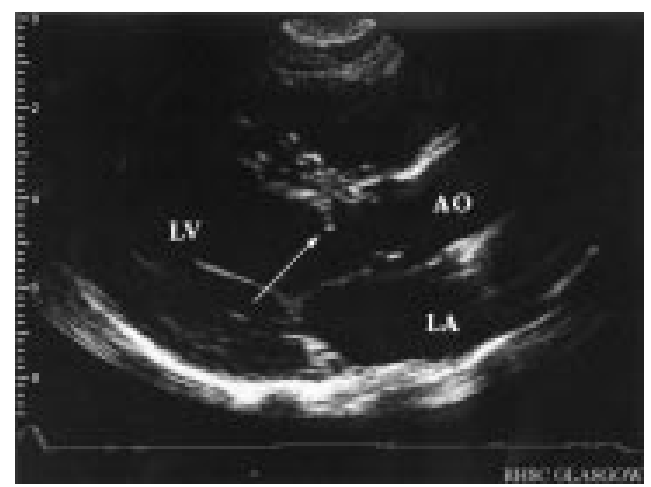

Figure 22 Long axis view in a patent with a subaortic membrane (arrow). 


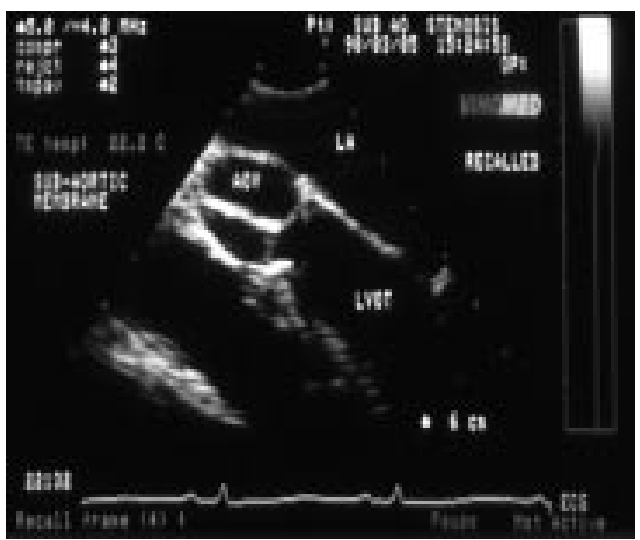

Figure 23 Transoesophageal echocardiography image of a subaortic membrane which is very closely related to the aortic valve and difficult to show with transthoracic imaging. AOV, aortic valve; LVOT, left ventricular outflow tract; others as before.

Table 9 Coarctation of the aorta

Suprasternal view of descending aorta for anatomy and presence of turbulent flow

Spectral measurement of maximum velocity and assessment of diastolic pattern

Remember imaging not a good technique for aneurysm assessment

- MRI more appropriate

Measure left ventricular systolic and diastolic dimensions and assess function

Quantify left ventricular hypertrophy

Assess aortic valve morphology, severity of regurgitation and

Doppler gradient

narrowing at the upper margin of the sinus of Valsalva or hypoplasia of a segment.

\section{Coarctation of the aorta}

Coarctation will not be detected with echocardiography unless there is clinical suspicion and suprasternal study is undertaken for abnormal flow in the descending aorta. In addition the presence of unexpectedly marked aorta dilation with aortic valve disease raises the question of an associated coarctation. The echocardiographic examination should concentrate on the assessment of obstruction or aortic dilatation at the coarctation site and aortic valve function (table 9).

The arch and descending aorta can be visualised from the suprasternal notch. Images sufficiently clear to show a coarctation can be obtained in children, ${ }^{48}$ but this may be difficult in adults and clear images of diffuse narrowing or a discrete shelf like constriction are seen only occasionally. ${ }^{49}$ Colour Doppler may highlight the area of abnormal flow and allow the narrowed area to be identified when this is not visible on the image. Transoesophageal study may add clarity. ${ }^{49}$ With a short axis view of the aorta the area of narrowing and turbulence is apparent as the probe is moved up or down; a long axis view will show the narrow segment better. MRI is a superior method of delineating aortic morphology. ${ }^{50}$ This is particularly important when following patients for aneurysm development; echocardiography should not be relied upon.

The spectral Doppler signal in significant obstruction is continuous with a mid-systolic peak and more gradual fall which continues

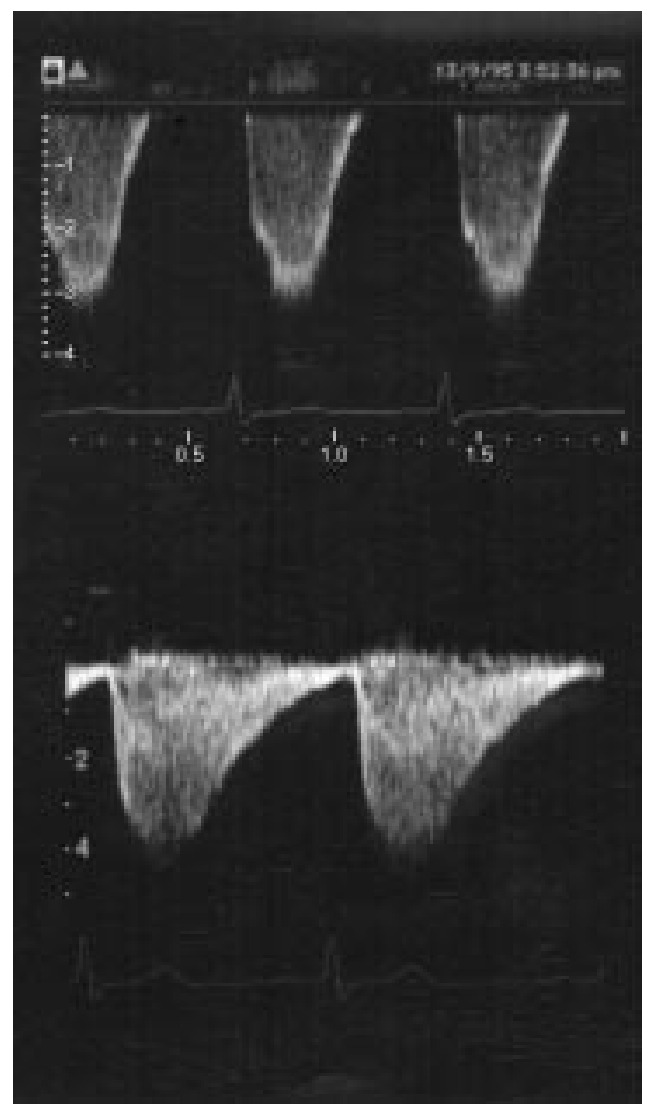

Figure 24 Spectral recordings of flow in the distal aortic arch from patients with mild (upper) and severe (lower) coarctation. In addition to the higher velocity of the severe obstruction the signal continues throughout diastole while in the less severe one the signal is only systolic.

Table 10 Ebstein's anomaly

Demonstrate anterior displacement of septal tricuspid leaflet on 4 chamber view

Study colour signal of tricuspid regurgitation and try to assess severity

Remember not to mistake the tricuspid ring (normal position) for the valve

with low velocity throughout diastole (fig 24). With less severe obstruction the signal may be of relatively high velocity but be entirely systolic (fig 24). The maximum Doppler and measured catheter gradients correlate poorly with both instantaneous and peak to peak values, whether performed in a primary coarctation $^{51}{ }^{52}$ or after surgery. ${ }^{53}$

\section{Ebstein's anomaly}

Ebstein's anomaly is characterised by variable degrees of apical displacement of the septal leaflet and regurgitation of the tricuspid valve. A four chamber view shows the apical displacement (fig 25) and regurgitation of the tricuspid valve (table 10). ${ }^{54}$ The tricuspid ring can usually be demonstrated in its normal position, and should not be mistaken for the tricuspid valve leaflets.

\section{Congenitally corrected transposition of the great arteries}

Corrected transposition of the great arteries is alternatively called l-transposition of the great arteries or, in morphological terms, situs 


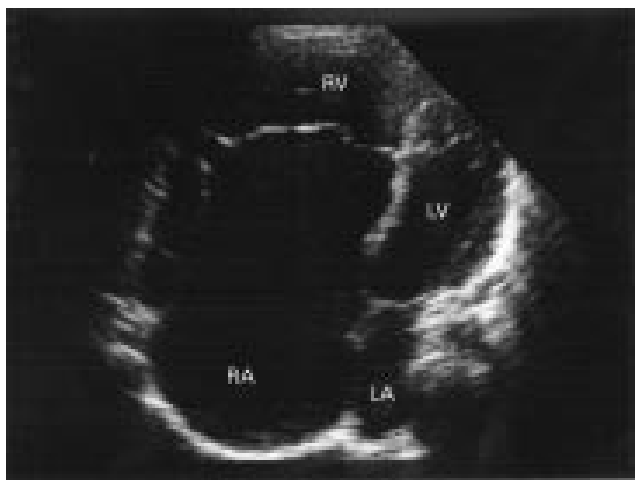

Figure 25 Four chamber view in a patient with Ebstein's anomaly of the tricuspid valve showing it to be apically displaced. The left ventricle (LV) and atrium (LA) are small and the right atrium $(R A)$ large consisting of the true atrium and the "atrialised" right ventricle (RV).

solitus with atrioventricular and ventriculoarterial discordance. It is particularly important to be able to diagnose this condition, which can be poorly recognised by adult cardiologists. Pulmonary stenosis, ventricular septal defect, or tricuspid valve anomalies are recognised associations. The systemic ventricle is a morphological right one and the tricuspid valve is often displaced, as in Ebstein's anomaly, and regurgitant.

Corrected transposition of the great arteries was long considered as a possible diagnosis if a satisfactory $M$ mode sweep could not be obtained and should be considered if there is difficulty in obtaining a long axis view (table 11). This occurs because the ventricular septum lies in a more anteroposterior plane than usual, and the aorta is positioned anteriorly and is separated by an infundibulum from the left sided inlet (tricuspid) valve. Echocardiographic diagnosis requires identification of the ventricular morphology. The tricuspid valve always enters the right ventricle; it is identified in a four chamber view by its more apical insertion into the ventricular septum (fig 26) or septal attachments of its chordae, and in a long axis view by discontinuity between it and the great artery outlet. The mitral valve enters the left ventricle, is nearer the crux of the heart, has no chordal attach-

Table 11 Corrected transposition of the great arteries

Consider the diagnosis if there is difficulty in obtaining a long axis view

Identify the left sided ventricle as a morphological right ventricle

- more apical position of its atrioventricular valve

- more apical position of its atrioventam

- discontinuity (infundibulum) between its inlet valve and great artery

Confirm the right sided ventricle as a morphological left ventricle

- less apical position of its atrioventricular valve

- chordae not attached to the septum

- continuity (no infundibulum) between its inlet valve and great artery

Demonstrate great artery roots as 2 circles in a short axis view

- identify the anterior left artery as aorta from its long upward course

- identify the posterior right artery as pulmonary artery from its branching

Assess any apical displacement or regurgitation of the tricuspid (left) valve

Check for presence of ventricular septal defect or pulmonary stenosis

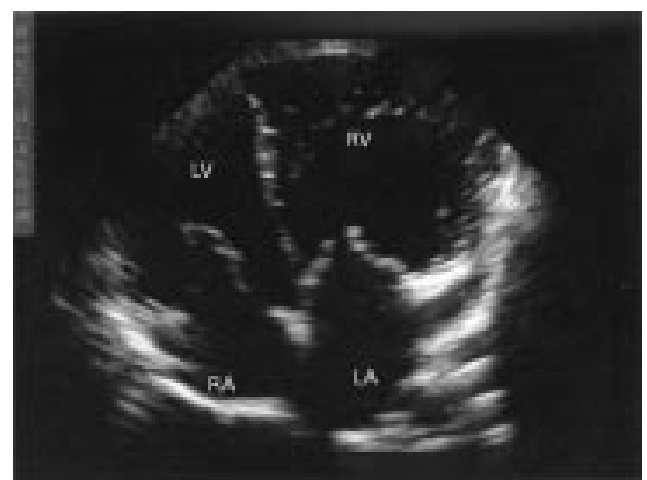

Figure 26 Four chamber view in a patient with corrected transposition of the great arteries. The left sided valve is more apically positioned indicating a left sided right ventricle (RV) and thus a right sided left ventricle (LV).

ments to the septum, and is continuous with the great artery. The aorta lies anterior and to the left of, and has a parallel upward course with, the pulmonary artery and a short axis view shows the great arteries as two circles with the left one (aorta) anterior and to the left of the right one (pulmonary artery). The arteries are identified by the long upward course of the aorta and the bifurcation of the pulmonary artery. It is important to evaluate the tricuspid valve in detail for any displacement and the degree of tricuspid regurgitation. ${ }^{55}$ The abnormal ventricular relation means that assessment of chamber sizes is difficult and normal accepted values for $M$ mode dimensions cannot be applied. Serial measurements from cross sectional images are worthwhile and can give some indication of progression.

\section{Cor triatriatum}

Cor triatriatum is a rare condition but it may well present in adult life and the literature contains many references to its diagnosis with ultrasound in adults. The pulmonary veins come together posteriorly but there is a membrane between their confluence and the mitral valve. This can obstruct pulmonary venous return and the condition may cause pulmonary venous hypertension or mimic mitral stenosis. The size of the orifice between the two parts of the left atrium determines the severity of obstruction and thus symptoms and age of presentation. Echocardiographically the condition is first suspected by the appearance of a linear structure in the left atrium in a long axis view and a four chamber view will confirm that this is a definite structure and not an artefact (table 12). Adjustment of the scanning plane may show the orifice and colour Doppler will confirm its location. Spectral Doppler can then be used to assess the pulmonary pressure from tricuspid regurgitation and measure the

\section{Table 12 Cor triatriatum}

Consider the diagnosis if a linear echo is found in the left atrium in long axis view

Confirm the presence of a linear echo in the left atrium in 4 chamber view

Show membrane orifice and increased velocity with colou Doppler

Measure maximum and mean velocity with spectral Doppler

Assess right ventricular pressure from signal of tricuspid regurgitation 
Table 13 Fontan procedure

Assess ventricular diastolic diameter and contraction Detect and quantify any left atrioventricular valve regurgitation Record pulmonary artery, pulmonary vein and hepatic vein spectral signal

Image Fontan circuit to detect any thrombus

Image and colour Doppler of Fontan circuit to detect any area of obstruction

Image and colour Doppler for a residual intra-atrial leak Transoesophageal imaging greatly improves quality of studies

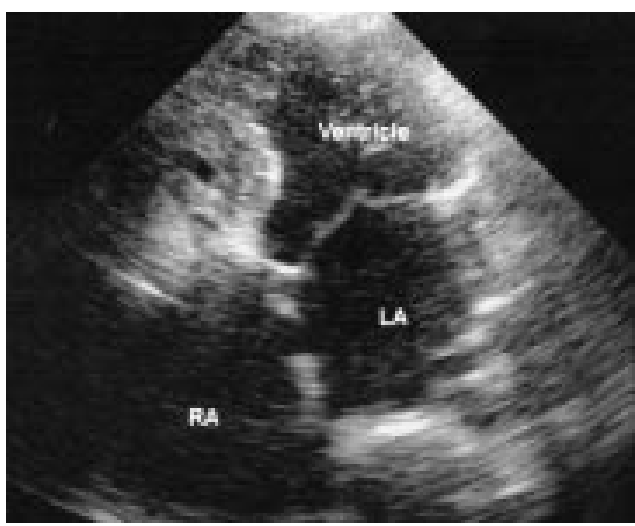

Figure 27 Four chamber view in a patient with tricuspid atresia and a Fontan repair. There is no apparent tricuspid valve and a single ventricular chamber. There appears to be a break in the atrial septum but this is echo dropout and none was demonstrated with colour imaging.

maximum and mean gradients across the membrane. It has been reported that severe obstruction is indicated by a maximum Doppler velocity of greater than $2 \mathrm{~m} / \mathrm{s} .{ }^{56}$ In difficult cases transoesophageal echocardiography readily shows the membrane ${ }^{57}$ and transmembrane gradients can also be measured.

\section{Fontan circuit}

The Fontan procedure ${ }^{58}$ and its various modifications are used to treat lesions characterised by the presence of only one adequately functioning ventricle, such as tricuspid atresia

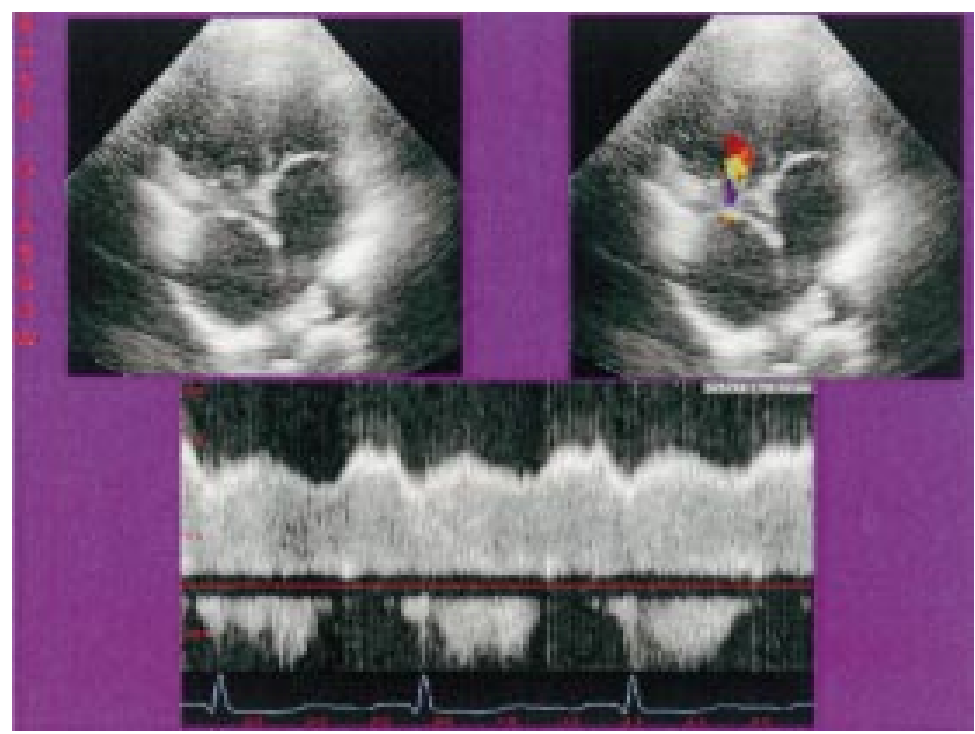

Figure 28 Transthoracic apical four chamber study of total cavopulmonary connection. The left image shows a double inlet ventricle and the proximity of the intra-atrial conduit to the right valve and the right shows colour flow through a surgically created fenestration and then through the atrioventricular valve to the ventricular chamber. The spectral Doppler trace of flow through the fenestration (below) shows right to left flow which is continuous and of relatively high velocity. or double inlet ventricle. The systemic venous blood is channelled directly into the pulmonary artery, bypassing the ventricle, while the oxygenated pulmonary venous blood returns to the left atrium and then to the single functioning ventricle and the aorta. The classic Fontan procedure connects the right atrium to the pulmonary artery directly by an anterior or posterior anastomosis. Modifications have included the use of intra- and extra-atrial conduits (with or without a valve), incorporation of a hypoplastic ventricular chamber into the circuit, and total cavopulmonary connection $^{59}$ (systemic veins to the right pulmonary artery, the superior vena cava directly and inferior vena cava by an intra- or extra-atrial tunnel). Raised pressure in the Fontan circuit (systemic venous pressure) can have a deleterious effect, either directly ${ }^{60}$ or from the development of arrhythmias which cause marked functional deterioration. Related factors are obstruction to the anastomosis or an increase in left atrial pressure from valve regurgitation or ventricular dysfunction. The use of echocardiography in the assessment and management of the Fontan patient has been reviewed in detail. ${ }^{61}$

The optimal planes for cross sectional imaging vary between individuals and all conventional views should be tried, including the right parasternal position. ${ }^{62}$ The appearances will vary with the underlying condition and the surgical approach which has been undertaken. Generally there is a single ventricle with an atretic or absent connection (fig 27) or two inlet valves (fig 28), one of which may have been closed off surgically. The scanning plane should be moved and angled to view the venous connections, atrium, and pulmonary arteries for thrombus (table 13). It is difficult to show areas of narrowing with cross sectional imaging alone and colour Doppler is less helpful in highlighting the narrowing than in other obstructive lesions because the velocities are low. Residual atrial shunting across leaks in the suture lines, an incompletely closed atrial septal defect, or a surgically created fenestration can be detected with colour Doppler (fig 28) or saline contrast injection. This is mainly right to left (fig 28), though spectral study can show brief flow in the other direction at the onset of systole. A rough measurement of the size of the defect may be obtained echocardiographically but functional severity is better assessed by saturation monitoring during exercise. Transoesophageal study is particularly useful in identifying thrombus, ${ }^{63}$ characterising atrial shunts, ${ }^{6465}$ and imaging posterior anastomoses, ${ }^{6466}$ but may not add much to the visualisation of anterior anastomoses.

SPECTRAL SIGNALS: ASSESSMENT OF SEVERITY OF OBSTRUCTION AND VENOUS PRESSURE

Pulmonary artery pressure and flow are determined by anastomotic or conduit obstruction, pulmonary vascular resistance, pulmonary venous atrial pressure (critically dependent on ventricular end diastolic pressure and atrioventricular valve function), and arguably the right atrial systolic function. ${ }^{6768}$ The pulmonary 


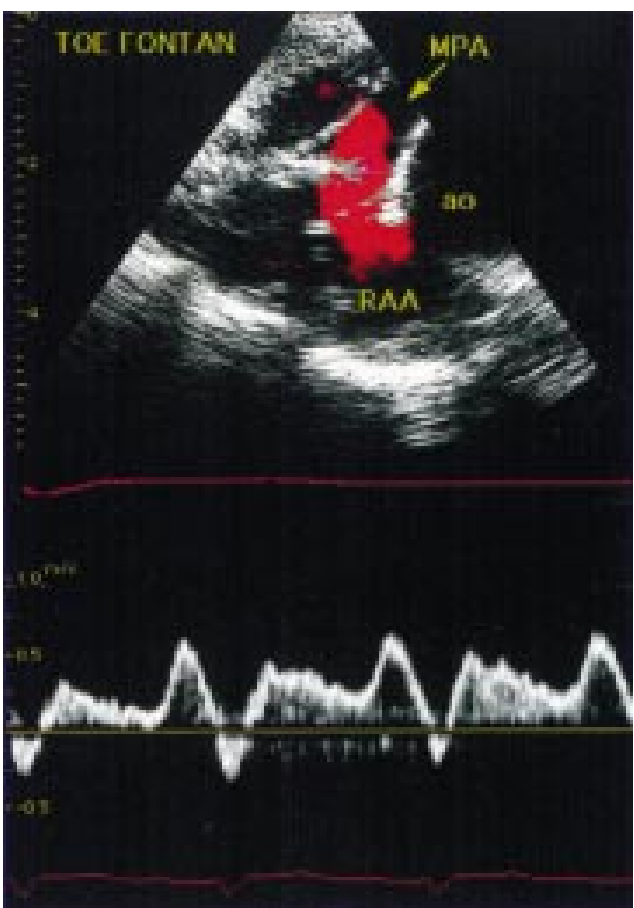

Figure 29 Transoesophageal study in a patient with a classic Fontan showing flow through the anastomosis and into the main pulmonary artery (MPA) on colour. The spectral signal (below) shows the typical triphasic appearance with forward flow (towards the transducer) in atrial systole followed by a brief retrograde flow in atrial relaxation and subsequent forward flow of lower velocity until atrial systole. RAA, right atrial appendage.

pressure will be the same as central venous pressure (or lower if there is an obstruction in the circuit) and cannot be estimated by ultrasound techniques. However, alterations in the pulmonary artery, hepatic vein, and pulmonary vein Doppler flow signals can reflect pressure changes in the Fontan circuit. ${ }^{69}{ }^{70}$ In a normal functioning Fontan, the pulmonary artery flow signal is typically triphasic ${ }^{71}$ (figs 29, 30). Initial forward flow occurs with right atrial systole, followed by retrograde flow during atrial relaxation. Forward flow is then restored, probably by a combination of the slightly
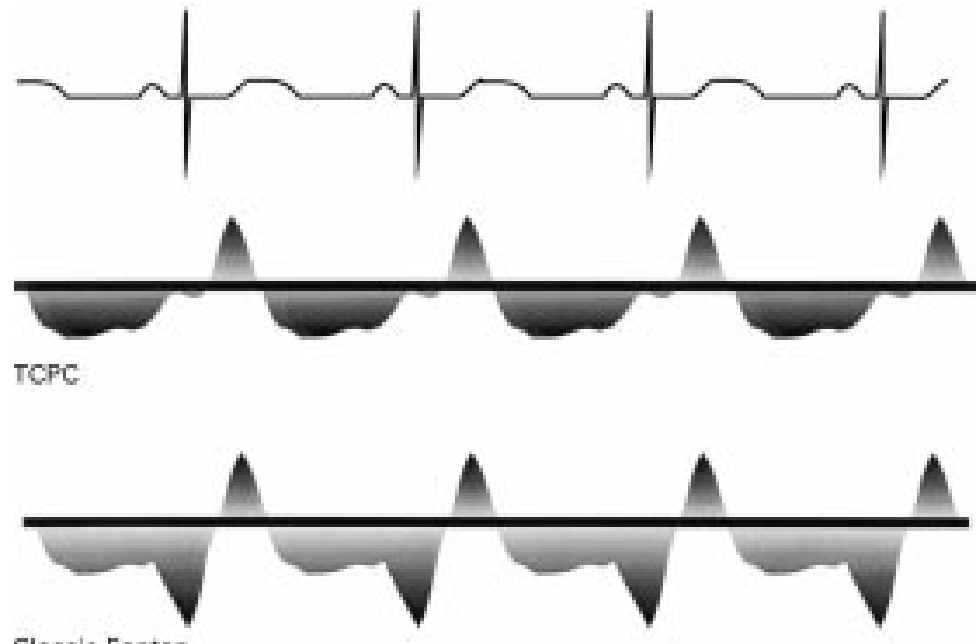

Classic Fontan

Figure 30 Diagrammatic representation of the spectral flow signals. With classic Fontan there is a distinct peak of forward flow with atrial systole, but this is lost in the total cavopulmonary connection (TCPC). delayed left atrial relaxation and systemic ventricular systole, with a second peak at the time of atrioventricular valve opening. ${ }^{70}$ In total cavopulmonary connection the right atrium has little or no influence, producing a biphasic signal with the increased velocity in atrial systole being absent (fig 30). All right sided flow patterns demonstrate increased forward velocities during inspiration and this is particularly marked in total cavopulmonary connection. ${ }^{6472}$ Because the pulmonary artery Doppler signal is a composite of left and right heart haemodynamics, serial analysis may prove useful in monitoring the effect of alterations in left heart function on the Fontan circuit; however, at present there are few data available to substantiate this. With anastomotic obstruction the pulmonary artery flow signal becomes more continuous with an increased mean velocity. In the future magnetic resonance velocity mapping techniques may improve on the Doppler assessment of pulmonary artery flow patterns. ${ }^{73}$

Atrioventricular valve regurgitation can increase pressure in the pulmonary venous bed and thus the Fontan circuit. The severity of atrioventricular valve regurgitation should be assessed using the standard methods. ${ }^{74}$ Systemic ventricular function is almost universally impaired $^{75}{ }^{76}$ and may progressively deteriorate. Assessment of ventricular function with echocardiography is difficult but may be informative if carried out using a consistent and well documented methodology. Radionuclide ventriculography may be a more useful technique.

\section{Transposition of the great arteries}

INFLOW CORRECTION: MUSTARD OR SENNING REPAIR

Transposition of the great arteries is characterised by origin of the aorta from the right ventricle and the pulmonary artery from the left. Until 10-20 years ago surgery took the form of redirection of venous flow by the Mustard or Senning procedure (fig 31). The right ventricle remains the systemic one and functional deterioration and tricuspid (systemic atrioventricular) valve regurgitation ${ }^{77} 78$ are key determinants of prognosis. It is also appropriate to check for baffle obstruction or leak, left ventricular outflow obstruction, or pulmonary hypertension although they are not likely to progress much after full growth has been attained (table 14). ${ }^{78}$ The echocardiographic features of Mustard and Senning repairs are similar.

\section{Table 14 Mustard or Senning procedure}

Measure right (systemic) ventricular size and assess function Assess systemic atrioventricular (tricuspid) regurgitation Use colour flow imaging to assess systemic or venous baffle obstruction

Use colour flow imaging to determine presence of baffle leak If appropriate use contrast to look for obstruction or leak Assess pulmonary pressure from velocity of mitral regurgitation

Exclude left ventricular outflow tract obstruction

Use transoesophageal imaging if precordial ones are not satisfactory

Remember the right ventricle is the systemic one and the left the pulmonary 


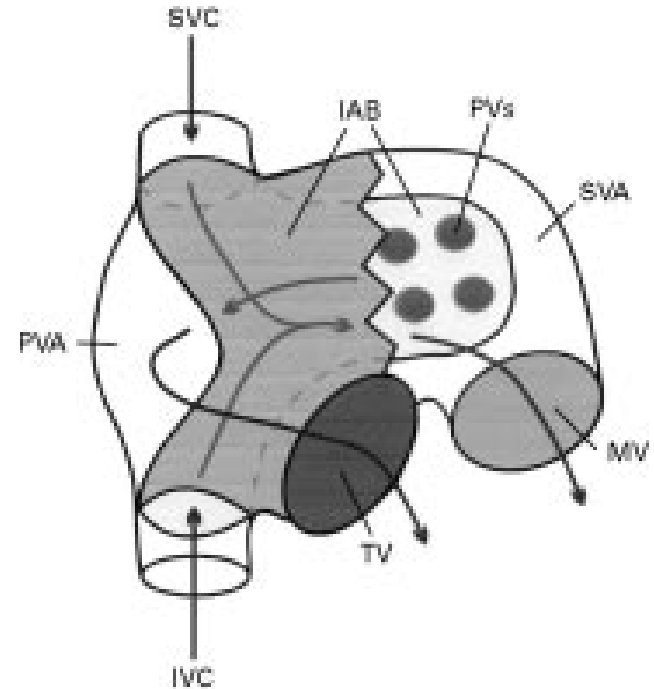

Figure 31 Schematic diagram demonstrating inflow redirection in the Mustard and Senning procedure. An intra-atrial baffle (IAB) is constructed from the mouth of each of the venae cavae and channelled to the left of the pulmonary veins to join and form a single channel directed to the mitral valve (MV) orifice. The pulmonary venous flow passes anterior to the inferior limb into the tricuspid valve (TV) orifice. IVC, inferior vena cava; $P V A$, pulmonary venous atrium; $P V$ s, pulmonary veins; $S V A$, systemic venous atrium; $S V C$, superior vena cava.

A long axis view in a patient with inflow correction and normal pulmonary artery pressure is striking in that the right ventricle is enlarged with the ventricular septum pushed posteriorly into a small, banana shaped left ventricle. This feature diminishes with increasing pulmonary pressure or, if there is a baffle leak, with volume load of the left ventricle. The ventricular morphology makes assessment of systemic ventricular function impossible using the techniques usually applied. ${ }^{79}$ Serial monitoring of right ventricular diastolic diameter is useful with an increase likely to indicate deterioration in function. Right ventricular systolic function is difficult to assess with echocardiography;

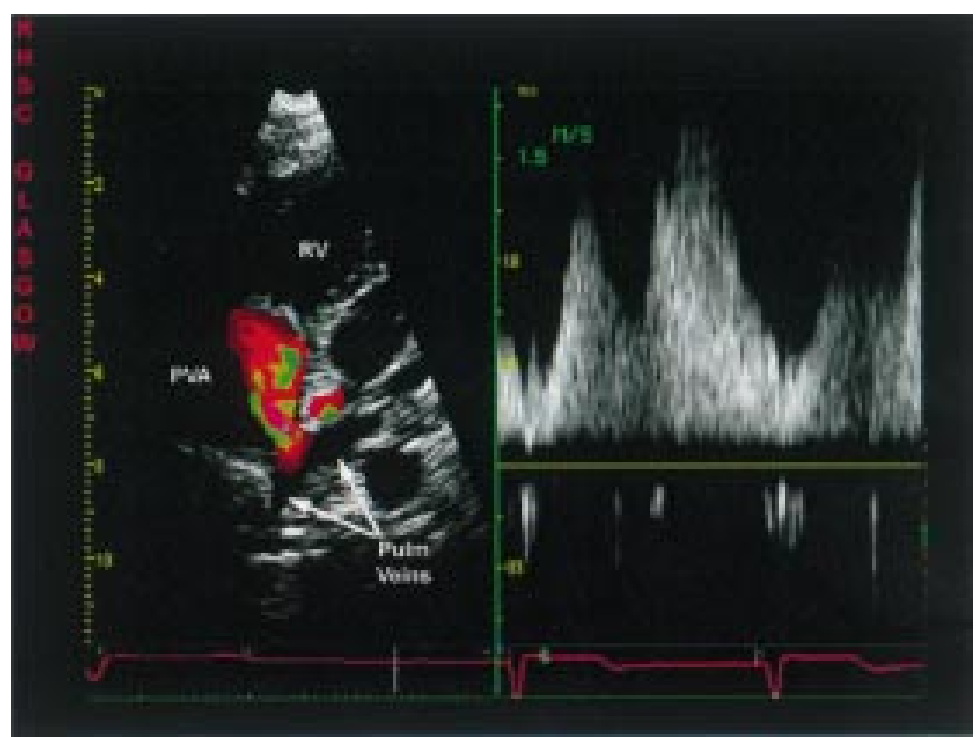

Figure 32 Modified subcostal transthoracic view in a Mustard correction with colour Doppler demonstrating flow acceleration through the pulmonary venous atrial anastomosis and the spectral signal showing continuous flow. PVA, pulmonary venous atrium; Pulm veins, pulmonary veins. ejection fraction correlates poorly with radionuclide assessment, questioning the value of such a measurement, particularly if it is a single one. ${ }^{80}$ An attempt to assess function from "eyeballing" contraction is very subjective but allows the extremes to be recognised. Tricuspid regurgitation is present in up to $70 \%$ of subjects ${ }^{77}$; although echocardiographic assessment of its severity is important the situation is not analogous to a normal heart.

\section{IDENTIFICATION OF BAFFLE OBSTRUCTION OR} LEAK

A reasonable approach to imaging the baffle is to start with an apical four chamber view showing the mitral valve and flow into it. The plane is then adjusted and tilted to follow the inferior limb to the inferior vena cava and the superior limb to the superior vena cava. Colour Doppler will help identify obstruction from increased flow velocity (fig 32). The pulmonary venous atrium is followed from its connection with the right ventricle to the pulmonary veins (fig 32). Transoesophageal imaging is often required to obtain diagnostic information. Its use with or without contrast is more sensitive in detecting all types of baffle malfunction, ${ }^{80}$ particularly pulmonary venous limb obstruction. ${ }^{81}$ The transverse plane readily visualises the superior limb, confluence, pulmonary venous atrium, and any baffle leak. The longitudinal plane can be difficult to interpret, but provides optimal imaging of the inferior limb. ${ }^{82}$ The spectral signal of flow from the venae cavae is a typical venous one, increasing in inspiration. Baffle obstruction results in a relatively small increase in peak velocity, perhaps up to $2 \mathrm{~m} / \mathrm{s}$, but the signal becomes continuous with reduced pulsatility ${ }^{83}$; also, the mean gradient rises, usually to about $3-5 \mathrm{~mm} \mathrm{Hg}$, similar to values obtained by direct measurement. Contrast echocardiography has been advocated for detecting superior limb obstruction by demonstrating flow down the azygous vein rather than into the heart. ${ }^{84}$ Contrast can assist in identifying the atria with filling of the systemic and "negative" imaging of the pulmonary venous atrium.

With a predominant systemic to pulmonary baffle leak there may be cyanosis, which will be worse on exercise. A pulmonary to systemic shunt is analogous to an atrial septal defect and may result in increase in size of the normally small left ventricle (fig 33). It has been reported that leaks producing a shunt of $25 \%$ or less are unlikely to be detected, ${ }^{83}$ although this may be improved by contrast studies.

Raised pulmonary pressure is common after the Mustard operation ${ }^{77}$ and should be assessed from the velocity of mitral regurgitation. Left ventricular outflow tract obstruction may develop secondary to the reversed roles of the two ventricles, with systolic bowing of the ventricular septum into the left ventricular outflow tract. Echocardiographic findings include systolic anterior movement of the anterior mitral valve leaflet, fluttering and premature closure of the pulmonary valve, and a dynamic, increased spectral signal from the left ventricular outflow tract. 


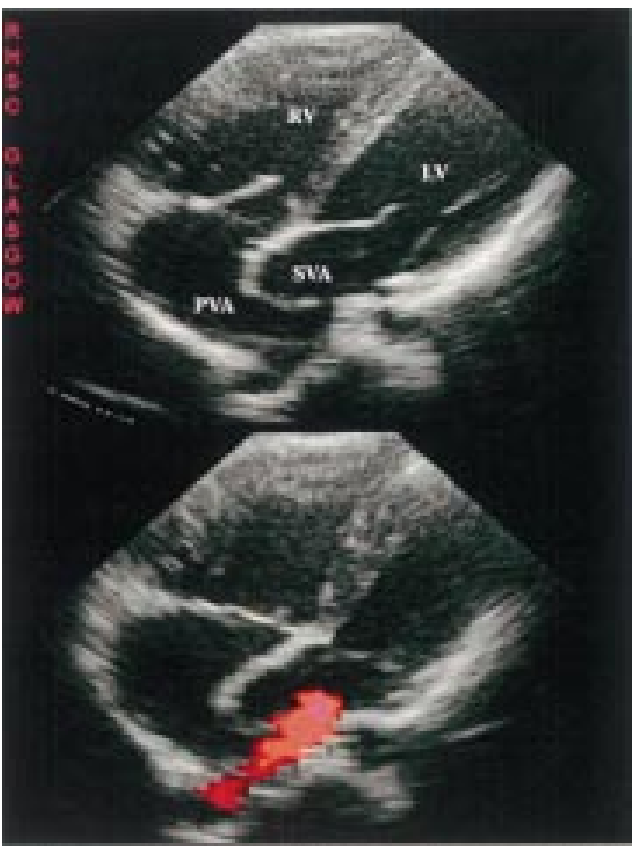

Figure 33 Parasternal four chamber views of patient with a Mustard procedure and pulmonary to systemic baffle leak. The upper image is in end diastole and shows the right ventricle $(R V)$ to be enlarged and hypertrophied but the left ventricular (LV) size is not reduced because of a pulmonary to systemic shunt. A right sided pulmonary vein is seen draining into the pulmonary venous chamber. The lower frame is taken in systole and colour Doppler shows a low velocity shunt through the baffle leak.

\section{ANATOMICAL REPAIR}

The arterial switch involves transection of the great arteries and reanastomosis to the other ventricular outlet, and reimplantation of the coronaries in the new aortic root. It has superseded inflow correction in the UK since the mid-1980s. The most common problems are narrowing of the pulmonary artery at the anastomotic site or in the branches from the stretching necessary to locate it in the anterior position. While pulmonary anastomotic stenosis can often be accurately assessed by transthoracic echocardiography, ${ }^{85}$ adequate imaging of the pulmonary branches may be impossible. ${ }^{86}$ Spectral Doppler does not give an accurate estimation of the severity of pulmonary branch narrowing. Assessment of right ventricular pressure may be the best technique for following this echocardiographically but MRI is much more sensitive at detecting branch narrowing in these patients. ${ }^{87}$

Aortic anastomosis obstruction is not common. Aortic regurgitation is frequently observed as a consequence of disruption of the suspensory apparatus of the cusps during anastomosis of the coronary buttons. It is seldom haemodynamically significant, ${ }^{86}$ but long term studies will be necessary to assess its progression.

11996 consensus conference on adult congenital heart disease. Commissioned by the Canadian Cardiovascular Society. Internet; Revised January 1998: http:// www.cachnet.org

2 Anderson RH. Simplifying the understanding of congenital malformations of the heart. Int $\mathcal{F}$ Cardiol 1991;32:131-42.

3 Huta JC, Smallhorn JF, Macartney FJ. Two dimensional echocardiographic diagnosis of situs. Br Heart f 1982:48: 97-108. 4 Huhta JC, Seward JB, Tajik AJ, et al. Two-dimensional
echocardiographic spectrum of univentricular atriovenechocardiographic spectrum of univentricular atrioven
tricular connection. $\mathcal{A} \mathrm{Am}$ Coll Cardiol 1985;5:149-57.

5 Eichhorn P, Sutsch G, Jenni R. New congenital heart abnormalities detected by echocardiography in adolescents and adults. Echokardiographisch Neu Entdeckte Kongenitale Vitien Und Anomalien Bei Adoleszenten Und Erwachsenen. Schweiz Med Wochenschr 1990;120:1697700 .

6 Berdjis F, Brandl D, Uhlemann F, et al. Erwachsene Mit Angeborenen Herzfehlern-Klinisches Spektrum Und Operative Behandlung. Herz 1996;21:330-36.

7 Shyu KG, Chen JJ, Huang ZS, et al. Role of transoesophageal echocardiography in the diagnostic assessment of cardiac sources of embolism in patients with acute ischaemic stroke. Cardiology 1994;85:53-60.

8 Cross SJ, Evans SA, Thomson LF, et al. Safety of subaqua diving with a patent foramen ovale. BMF 1992;304:481-2.

9 Eichhorn P, Vogt P, Ritter M, et al. Malformations of the interatrial septum: recognition, prevalence and clinical relinteratrial septum: recognition, prevalence and clinical rel41 .

10 Diamond MA, Dillon JC, Haine CL, et al. Echocardiographic features of atrial septal defects. Circulation 1971;43: 129-35.

11 Chen C, Kremer P, Schroeder E, et al. Usefulness of anatomic parameters derived from two-dimensional echocardiography for estimating magnitude of left to right shunt in patients with atrial septal defect. Clin Cardiol 1987;10: 316-21.

12 Shub C, Dimopoulos IN, Seward, et al. Sensitivity of two-dimensional echocardiography in the direct visualization of atrial septal defect utilizing the subcostal approach. $7 \mathrm{Am}$ Coll Cardiol 1983;2:127-35.

13 Kronzon I, Tunick PA, Freedberg RS, et al. Transoesophageal echocardiography is superior to transthoracic echocardiography in the diagnosis of sinus venosus atrial septal cardiography in the diagnosis of sinus ven
defect. A Am Coll Cardiol 1991;17:537-42.

14 Gnanapragasam JP, Houston AB, Northridge DB, et al. Transoesophageal echocardiographic assessment of primum, secundum, and sinus venosus atrial septal defects. Int $\mathcal{F}$ Cardiol 1991;31:167-74.

15 Minich LL, Snider AR. Echocardiographic guidance during placement of the buttoned double-disc device for atrial septal defect closure. Echocardiography 1993;10:567-72.

16 Hagen PT, Scholz DG, Edwards WD. Incidence and size of patent foramen ovale during the first 10 decades of life: an autopsy study of 965 normal hearts. Mayo Clin Proc 1984; 59:17-20.

17 Belkin RN, Pollack BD, Ruggier ML, et al. Comparison of trans-oseophageal and trans-thoracic echocardiography with contrast and colour flow in the detection of patent foramen ovale. Am Heart f 1994;128:520-5.

18 Belkin RN, Waugh RA, Kisslo J. Interatrial shunting in atrial septal aneurysm. Am f Cardiol 1986;57:310-2.

19 Mascarenhas E, Javier RP, Samlet P. Partial anomolous venous connection and drainage. Am f Cardiol 1973:31: $512-8$.

20 Hagler DJ, Tajik AJ, Seward JB, et al. Real-time wide angle sector echocardiography: atrioventricular canal defects. Circulation 1979;59:140-50.

21 Smallhorn JF, Tommasini G, Anderson RH, Macartney FJ. Assessment of atrioventricular defects by two-dimensional echocardiography. Br Heart f 1982;47:109-21.

22 Mortera C, Rissech M, Payola M, et al. Cross sectional subcostal echocardiography: atrioventricular septal defects and the short axis cut. Br Heart $\mathcal{f} 1987 ; 58: 267-73$.

23 Smallhorn JF, Huhta JC, Anderson RH, et al. Suprasternal echocardiography in assessment of patent ductus arterioechocardiography in assessment
sus. Br Heart f 1 1982;48:321-30.

24 Swensson RE, Valdes Cruz LM, Sahn DJ, et al. Doppler colour flow mapping for detection of patent arterial ductus. $\mathcal{F}$ Am Coll Cardiol 1986;8:1105-12.

25 Chen YT, Lee YS, Kan MN, et al. Transesophageal echocardiography in adults with a continuous precordial murmur. Int f Cardiol 1992;36:61-8.

26 Shyu KG, Lai LP, Lin SC, et al. Diagnostic accuracy of transesophageal echocardiography for detecting patent ductus arteriosus in adolescents and adults. Chest 1995; 108:1201-5.

27 Houston AB, Gnanapragasam JP, Doig WB, et al. Doppler ultrasound and the silent ductus arteriosus. Br Heart $\mathcal{f}$ 1991;65:148-51.

28 Sapin P, Frantz E, Jain A, et al. Coronary artery fistula: an abnormality affecting all age groups. Medicine 1990;69: 101-13.

29 Rodgers DM, Wolf NM, Barrett MJ, et al. Two-dimensional echocardiographic features of coronary arteriovenous fistula. Am Heart f 1982;104:872-4.

30 Ke WL, Wang NK, Lin YM, et al. Right coronary artery fistula into right atrium: diagnosis by color Doppler echocardiography. Am Heart $\mathcal{F}$ 1988;116:886-9.

31 Jain SP, Mahan EF III, Nanda NC, et al. Doppler color flow mappping in the diagnosis of sinus of Valsalva aneurysm. Echocardiography 1989;6:533-8.

32 Sutherland GR, Godman MJ, Smallhorn JF, et al. Ventricular septal defects. Two dimensional echocardiographic and
morphological considerations. Br Heart f 1982;47:316-28.

33 Hagler DJ, Edwards WD, Seward JB, et al. Standardised nomenclature of the ventricular septum and ventricular septal defects, with applications for two-dimensional echoseptal defects, with applications for two-dimension
cardiography. Mayo Clin Proc 1985;60:741-52.

34 Murphy DJ, Ludomirsky A, Huhta JC. Continuous wave Doppler in children with ventricular septal defect: noninva- 

sive estimation of interventricular pressure gradient. Am $\mathcal{F}$

35 Houston AB, Lim MK, Doig WB, et al. Doppler assessment of the interventricular pressure drop in VSD. Br Heart $\mathcal{F}$ 1988;60:50-6.

36 Craig BG, Smallhorn JF, Burrows P, et al. Cross-sectional echocardiography in the evaluation of aortic valve prolapse associated with ventricular septal defect. Am Heart F 1986; 112:800-7.

37 Mulhern KM, Skorton DJ. Echocardiographic evaluation of isolated pulmonary valve disease in adolescents and adults. Echocardiography 1993;10:533-43.

38 Hutchison SJ, Rosin BL, Curry S, et al. Transesophageal assessment of lesions of the right ventricular outflow tract and pulmonary valve. Echocardiography 1996;13:21-34.

39 Lima CO, Sahn DJ, Valdes Cruz LM. Non invasive prediction of transvalvular pressure gradient in patients with pulmonary stenosis by quantitative two dimensional echocardiographic studies. Circulation 1983;67:866-71.

$40 \mathrm{Lim}$ MK, Houston AB, Doig WB, et al. Variability of the Doppler gradient in pulmonary valve stenosis before and after balloon dilatation. Br Heart $\mathcal{F}$ 1989;62:212-6.

41 Jobic Y, Slama M, Tribouilloy C, et al. Doppler echocardiography evaluation of valve regurgitation in healthy volunteers. Br Heart f 1993:69:109-13.

42 Jonsson $\mathrm{H}$, Ivert T, Brodin LA. Echocardiographic findings in 83 patients 13-26 years after intracardiac repair of tetralogy of Fallot. Eur Heart $\mathcal{f}$ 1995:16;1255-63.

43 Canter CE, Gutierrez FR, Molina P, et al. Noninvasive diagnosis of right-sided extracardiac conduit obstruction by combined magnetic resonance imaging and continuouswave Doppler echocardiography. 7 Thorac Cardiovasc Surg 1991;1014:724-31.

44 Di Sessa TG, Hagan AD, Isobel-Jones JB, et al. Twodimensional echocardiographic evaluation of discrete subaortic stenosis from the apical long axis view. Am Heart $\mathcal{F}$ 1981;101:774-82.

45 Mugge A, Daniel WG, Wolpers HG, et al. Improved visualisation of discrete subvalvar aortic stenosis by transesophasation of discrete subvalvar aortic stenosis by transesopha-
geal color coded Doppler echocardiography. Am Heart $\mathcal{F}$ geal color coded

46 Gnanapragasam JP, Houston AB, Doig WB, et al. Transoesophageal echocardiographic assessment of fixed subaortic stenosis in children. Br Heart $\mathcal{F}$ 1991;66:281-4

47 Davis RH, Feigenbaum H, Chang S, et al. Echocardiographic manifestations of discrete subaortic stenosis. Am $\mathcal{F}$ Cardiol 1974;33:277-80

48 Duncan WJ, Ninimiya K, Cook DH, et al. Noninvasive diagnosis of neonatal coarctation and associated anomalies using two-dimensional echocardiography. Am Heart $f$ 1983;106:63-9.

49 Engvall J, Sjogvist L, Nylander E, et al. Biplane transesophageal echocardiography, transthoracic Doppler, and magnetic resonance imaging in the assessment of coarctation of the aorta. Eur Heart f 1995;16:1399-409.

50 Rees S, Somerville J, Ward C, et al. Coarctation of the aorta: magnetic resonance imaging in the late post-operative assessment. Radiology 1989;173:499-502.

51 Houston AB, Simpson IA, Pollock JCS, et al. Doppler ultrasound in the assessment of severity of coarctation of the
aorta and interuption of the aortic arch. Br Heart $\mathcal{f}$ aorta and interup

52 Rao PS, Carey P. Doppler ultrasound in the prediction of pressure gradients across aortic coarctation. Am Heart $\mathcal{f}$ 1989;118:299-307

53 Chan KC, Dickinson DF, Wharton GA, et al. Continuous wave Doppler echocardiography after surgical repair of coarctation of the aorta. Br Heart f 1992;68:192-4.

54 Shiina A, Seward JB, Edwards WD. Two-dimensional echocardiographic spectrum of Ebstein's anomaly. Detailed anatomic assessment. $\mathcal{7}$ Am Coll Cardiol 1984:3:35670.

55 Hopkins WE, Waggoner AD, Davila-Roman V, et al. Two-dimensional Doppler color flow imaging in adults with L-transposition of the great arteries. Echocardiography 1993;10:611-17.

56 Vick GW III, Murphy DJ Jr, Ludomirsky A, et al. Pulmonary venous and systemic ventricular inflow obPulmonary venous and systemic ventricular infow obstruction in patients with congenital heart disease:
Detection by combined two-dimensional and Doppler Detection by combined two-dimensional and Dop

57 Hoffmann R, Lambertz H, Flachskampf FA, et al. Transoesophageal echocardiography in the diagnosis of cor triatriatum; incremental value of colour Doppler. Eur Heart f 1992;13:418-20.

58 Fontan F, Baudet E. Surgical repair of tricuspid atresia. Thorax 1971;26:240-8

59 de Leval MR, Kilner P, Deville C, et al. Total cavopulmonary connection: a logical alternative to atriopulmonary connection for complex Fontan operations. Experimental studies and early clinical experience. 7 Thorac Cardiovasc Surg 1988;96:682-90.

60 Bull K. The Fontan procedure: lessons from the past. Heart 1998;79:213-14.

61 Hagler DJ, Cordes TM. Complete echocardiographic assessment of the postoperative Fontan patient. Echocardiography 1995;12:529-43.
62 Marcella CP, Johnson LE. Right parasternal imaging: an under-utilised echocardiographic technique. $7 \mathrm{Am}$ Soc Echo 1993;6:453-66.

63 Fyfe DA, Kline CH, Sade RM, et al. Transoesophageal echocardiography detects thrombus formation not identified by transthoracic echocardiography after the Fontan operation. F Am Coll Cardiol 1991;18:1733-7.

64 Stumper O, Sutherland GR, Geuskens R, et al. Transoesophageal echocardiography in evaluation and management after a Fontan procedure. 7 Am Coll Cardiol 1991;17: $1152-60$.

65 Van Hare GF, Silverman NH. Contrast 2-dimensional echocardiography in congenital heart disease: techniques, indications and clinical utility. $\mathcal{F}$ Am Coll Cardiol 1989;13: 673-86.

66 Sreeram N, Sutherland GR, Geuskens R, et al. The role of transoesophageal echocardiography in adolescents and adults with congenital heart defects. Eur Heart $\mathcal{F}$ 1991;12: 231-40.

67 Qureshi SA, Richeimer R, McKay R, et al. Doppler echocardiographic evaluation of pulmonary artery flow after modified Fontan operation: importance of atrial contraction. $\mathrm{Br}$ Heart f 1990;64:272-6.

68 Alboliras ET, Porter C, Danielson GK, et al. Results of the modified Fontan operation for congenital heart lesions in patients without pre-operative sinus rhythm. F Am Coll Cardiol 1985;6:228-33.

69 Frommelt PC, Snider R, Meliones JN, et al. Doppler assessment of pulmonary artery flow patterns and ventricular function after the Fontan operation. Am f Cardiol 1991;68: 1211-5

70 DiSessa TG, Child JS, Perloff JK, et al. Systemic venous and pulmonary arterial flow patterns after Fontan's procedure or tricuspid atresia or single ventricle. Circulation 1984;70: 898-902.

71 Hatle L. Non-invasive assessment of the Fontan circulation. In: Hess JSG, ed. Congenital heart disease in adolescents and adults. New York: Kluwer Academic, 1992;136:125-32.

72 Penny DJ, Redington AN. Doppler echocardiographic evaluation of pulmonary blood flow after the Fontan operation: the role of the lungs. Br Heart f 1991;66:372-4.

73 Rebergen SA, Ottenkamp J, Doornbos J, et al. Postoperative flow dynamics after Fontan surgery: assessment with nuclear magnetic resonance velocity mapping. F Am Coll Cardiol 1993;21:123-31.

74 Simpson IA, de Belder MA, Kenny A, et al. How to quantitate valve regurgitation by echo Doppler techniques. $\mathrm{Br}$ Heart F 1995;73(suppl 2):1-9.

75 Harrison DA, Liu P, Walters JE, et al. Cardiopulmonary function in adult patients late after Fontan. $7 \mathrm{Am}$ Coll Cardiol 1995;26:1016-21.

76 Fontan F, Kirklin JW, Fernandez G, et al. Outcome after a "perfect" Fontan operation. Circulation 1990;81:1520-36.

77 Sagin-Saylam G, Sommerville J. Palliative Mustard operation for transposition of the great arteries: late results after 15-20 years. Heart 1996;75:72-7.

78 Redington AN, Rigby ML, Oldershaw $\mathrm{P}$, et al. Right ventricular function 10 years after the Mustard operation for transposition of the great arteries: analysis of size, shape and wall motion. Br Heart 7 1989;62:455-61.

79 Silverman NH, Payot M, Stanger P, et al. The echocardiographic profile of patients after Mustard's operation. Circulation 1978;58:1083-93.

80 Wilson NJ, Neutze J, Rutland MD, et al. Transthoracic echocardiography for right ventricular function late after the Mustard operation. Am Heart f 1996;131:360-7.

81 Sutherland GR, Stumper O. Transoesophageal echocardiography in congenital heart disease. Acta Paediatrica Suppl 1995;410:15-22.

82 Kaulitz R, Stumper O, Geuskens R, et al. Comparative values of the precordial and transoesophageal approaches to the echocardiographic assessment of atrial baffle function after an atrial correction procedure. $\mathcal{F} \mathrm{Am}$ Coll Cardiol 1990;16:686-94

83 Cromme-Dijkhuis AH, Schasfoort-van Leeuwen M, BinkBoekens MT, et al. The value of 2-D doppler echocardiography in the evaluation of assymptomatic patients with Mustard operation for transposition of the great arteries. Eur Heart $\mathcal{f} 1991 ; 12: 1308-10$.

84 Silverman NH, Snider A, Colo J, et al. Superior venocaval obstruction after Mustard's operation: detection by twodimensional contrast echocardiography. Circulation 1981; 64:392-6.

85 Salzer-Muhar U, Proll E, Marx M, et al. Two-dimensional and doppler echocardiographic follow-up after the arterial switch operation for transposition of the great arteries. Thorac Cardiovasc Surg 1991;39(suppl 2):180-4.

86 Gibbs JL, Quereshi SA, Grieve L, et al. Doppler echocardiography after anatomical correction of transposition of the great arteries. Br Heart $\mathcal{F}$ 1986;56:67-72.

87 Blankenberg F, Rhee J, Hardy C, et al. MRI vs echocardiography in the evaluation of the Jantene procedure. 7 Comp Assisted Tomogr 1994;18:749-54. 